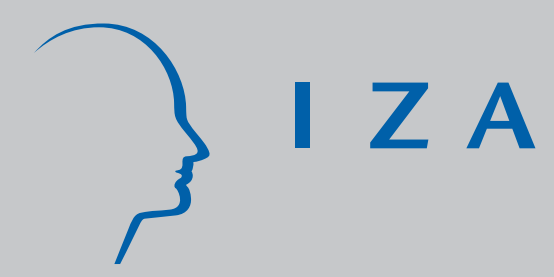

IZADP No. 1676

Should the U.S. Have Locked the Heaven's Door? Reassessing the Benefits of the Postwar Immigration

Xavier Choj nicki

Frédéric Docquier

Lionel Ragot

July 2005 


\title{
Should the U.S. Have Locked the Heaven's Door? Reassessing the Benefits of the Postwar Immigration
}

\author{
Xavier Chojnicki \\ MÉDEE, University of Lille 1 and CEPII \\ Frédéric Docquier \\ CADRE, University of Lille 2, \\ World Bank and IZA Bonn \\ Lionel Ragot \\ MÉDEE, University of Lille 1 \\ and EUREQua, University of Paris 1
}

Discussion Paper No. 1676

July 2005

IZA

P.O. Box 7240

53072 Bonn

Germany

Phone: +49-228-3894-0

Fax: +49-228-3894-180

Email: iza@iza.org

\begin{abstract}
Any opinions expressed here are those of the author(s) and not those of the institute. Research disseminated by IZA may include views on policy, but the institute itself takes no institutional policy positions.

The Institute for the Study of Labor (IZA) in Bonn is a local and virtual international research center and a place of communication between science, politics and business. IZA is an independent nonprofit company supported by Deutsche Post World Net. The center is associated with the University of Bonn and offers a stimulating research environment through its research networks, research support, and visitors and doctoral programs. IZA engages in (i) original and internationally competitive research in all fields of labor economics, (ii) development of policy concepts, and (iii) dissemination of research results and concepts to the interested public.
\end{abstract}

IZA Discussion Papers often represent preliminary work and are circulated to encourage discussion. Citation of such a paper should account for its provisional character. A revised version may be available directly from the author. 


\section{ABSTRACT}

\section{Should the U.S. Have Locked the Heaven's Door? Reassessing the Benefits of the Postwar Immigration*}

This paper examines the economic impact of the second great immigration wave (19452000) on the US economy. Contrary to recent studies, we estimate that immigration induced important net gains and small redistributive effects among natives. Our analysis relies on a computable general equilibrium model combining the major interactions between immigrants and natives (labor market impact, fiscal impact, capital deepening, endogenous education, endogenous inequality). We use a backsolving method to calibrate the model on historical data and then consider two counterfactual variants: a cutoff of all immigration flows since 1950 and a stronger selection policy. According to our simulations, the postwar US immigration is beneficial for all cohorts and all skill groups. These gains are closely related to a long-run fiscal gain and a small labor market impact of immigrants. Finally, we also demonstrate that all generations would have benefited from a stronger selection of immigrants.

JEL Classification: J61, I3, D58

Keywords: immigration, inequality, welfare, computable general equilibrium

Corresponding author:

Frédéric Docquier

University of Lille 2

1 Place Déliot

F-59024 Lille

France

Email: f.docquier@skynet.be

\footnotetext{
* We are grateful to Alan Auerbach, Tim Miller and Philip Oreopoulos for transmitting their dataset. We thank the participants to the Conference on Overlapping Generation (La Rochelle, 2004) and T2M (Lyon, 2005) for helpful comments. The usual disclaimers apply.
} 


\section{Introduction}

Modern American history is characterized by two noticeable immigration periods. The first immigration wave started in 1891 and culminated in 1900 with almost 9 millions legal immigrants. Then, between 1920 and 1950, the stock of immigrants vanished. The second wave started in 1950 and has not yet come to an end. By the late 1990s, nearly one million legal immigrants are annually entering the country. The stock of foreign-born amounts to about 10 percent of the population. This second wave of immigration can be divided in two sub-periods. Before 1965, the immigration policy was ruled by a system of quotas based on national origin. Each sending country's share in the total number of visas was determined by the representation of that ethnic group in the US population as of 1920. Consequently, the United Kingdom and Germany received about $65 \%$ of the available visas. This quota-based scheme disappeared with the 1965 Amendments to the Immigration and Nationality Act, relying on new constraints (a worldwide numerical limit to the number of visas) and new objectives (family reunification). This new policy has considerably changed the national origin mix of immigrants. By the 1990s, more than 80 percent of legal immigrants originated in Asian and Latin American countries while European immigrants only represent 16 percent. This change in the origin mix translated into a deep change in the relative skills of immigrants. Their skills and economic performance have declined compared to those of natives. One should not be surprised that a number of US policymakers and economists are today worrying about the economic impact of immigration, especially the effect on natives' income and well-being. In his remarkable book Heaven's door, George Borjas recently argued that the recent US immigration policy induces small annual net gains and an astonishing transfer from the poorest to the richest people. Focusing on the postwar period and relying on a unified general equilibrium model, this paper examines whether some natives would have gained from (partially or totally) locking the heaven's door.

The impact of immigration on natives' welfare can essentially be related to two mechanisms:

- the first one refers to the impact of immigration on the productivity of factors supplied by the natives (and hence on prices, wages and the return on saving). On the one hand, immigration (especially unskilled immigration) is likely to reduce the capital per efficiency unit of labor, leading to decreasing wages and increasing interest rates. On the other hand, new immigrants are competing with natives on the labor market, especially on the market for low-skill workers. This induces downward pressures on unskilled workers' wages and upward pressures on the skill premium. The empirical literature provides mitigated results on the labor market outcome of immigration. Spatial correlations between natives' wages and immigrant stock are extremely weak: as surveyed by Friedberg and Hunt (1995), if one city has 10 percent more immigrants, the native wage decreases by .2-.7 percent only. Borjas, 
Freeman and Katz (1997) questioned the validity of interpreting weak spatial correlation as evidence of a minor impact on the labor market. If migrants endogenously cluster in thriving economies and/or if natives respond to the local labor market changes by moving their labor or capital to other cities, the adverse impact of immigration will be diffused over the entire economy. For these reasons, the labor market impact of immigration must be measured at the national level rather than at the local level. Applying the "factor proportions approach" to national data, Borjas (2003) concluded that a 10 percent increase in labor supply could reduce wages by $3-4$ percent;

- the second mechanism refers to the use of social services. Low-skill immigrants are making extensive use of welfare transfers and place a substantial fiscal burden on the natives ${ }^{1}$. This is particularly true as immigrants are likely to select their location on the basis of welfare generosity (Borjas, 1999a). Welfare programs are attracting immigrants who qualify for subsidies and are deterring out-migration. Existing studies reveal that the fiscal impact of immigration depends on whether one uses short-run or long-run approach. Accounting for expenditures incurred and tax collected, short-run studies found out that immigrants initially create a burden for native taxpayers. As they assimilate, have children and grand-children, the immigrants' contribution to the economy becomes positive: a long-run fiscal gain is obtained.

Combining these effects in a unified framework is a complex task. Calculating the immigration surplus requires accurate information about how the wage of each particular skill group responds to immigration, about the impact on the capital stock per worker... Evaluating the redistributive effect of immigration implies disentangling the wage inequality impact of many factors such as immigration, capital deepening, skill biased technical changes, total factor productivity growth, changes in educational attainment among natives. Taking account of the fiscal burden needs a complete modeling of the public sector. Examining the global impact on the natives' well-being requires modeling the microfoundations of individual behavior. The purpose of this paper is to examine the global impact of the second great immigration wave (1950-2000) in a computable general equilibrium framework with overlapping generations of heterogeneous agents closely related to Auerbach and Kotlikoff (1987). Two related studies are Storesletten (2000) and Fehr and al. (2004) who investigate whether a reform of immigration policies could alone attenuate the fiscal burden of aging in coming decades. Compared to these studies, our paper focuses on the post-war period. Using counterfactual experiments, we compute the hypothetical transition path of the US economy under hypothetical immigration variants. Furthermore, our model strongly emphasizes the effects of immigration on the labor market, on the public sector and its interaction with technical changes.

\footnotetext{
${ }^{1}$ See Borjas (1994), Lee and Miller (1997, 2000), Bonin and al. (2000), Auerbach and Oreopoulos (2000) on the public finance impact of immigration.
} 
The model relies on a complex socio-demographic block that uses historical data on education choices, fertility, mortality, in-migration and out-migration. Within each generation, individuals are distinguished by their skill level (low-, medium- and high-skill) and by their origin (immigrants and natives). Hence, natives and immigrants differ in terms of human capital. This contrasts with Fehr and al. (2004) who consider that immigrants automatically become natives (in an economic sense) after crossing the border. As in Storesletten (2000), we assume that the skills of second-generation immigrants are independent of the skills of their parents (second-generation immigrants behave as natives).

We demonstrate that the way immigrants affect wages and inequality is strongly depending on the choice of a production function. Hence, an important feature of our model is that labor in efficiency units is made of three major components: raw labor, experience and educational attainment. Our approach is highly compatible with the Mincerian literature on wage determination, emphasizing the contribution of these three components on the labor market outcome. Building on Ben Porath (1967), Card and Lemieux (2001) or Wasmer (2001a), we combine these components according to a constant elasticity of substitution technological function. The minimum wage, the return on experience and the skill premium are determined endogenously and depends on productivity changes (introduced to capture economic growth and changes in the skill premium). Card and Lemieux (2001) and Borjas (2003) use a similar approach by distinguishing workers according to their education and their experience. The supplies of labor by "skill/experience" group are then combined in nested CES transformation functions (the number of embedded CES functions depends on how many groups they consider). In our model, each individual offers a quantity of experience and a quantity of education-related human capital. We consider the stocks of education and experience as homogenous. Our production function is then independent on the number of periods of life and education groups distinguished. The average experience and education level of immigrants differ from that of natives. Immigrants and native workers are thus imperfect substitutes on the US labor market.

We calibrate the model on the post-war period, using demographic data, detailed profiles for transfers, observations for educational attainment, retirement age and participation rates. Exogenous unobserved processes (such as skill-biased and unbiased technical changes) are identified by letting the model match the US economic path over the post-war period. Basically, our identification process resembles Sims (1990) backsolving method for stochastic general equilibrium models. We use a similar idea of treating exogenous processes as endogenous, not to solve a model, but as a calibration device in a deterministic framework. Starting from the calibrated model, we simulate two hypothetical immigration variants: a cutoff of immigration flows after 1950 and a stronger selection of the postwar cohorts of immigrants.

Our results contrast with the common views. In theory, immigration induces redistributive effects 
and influences the size of the economic pie to be shared within the whole population. Contrary to Borjas (1999b), we find out important net economic gains from immigration but moderate redistributive implications. According to our simulations, the postwar US immigration is beneficial for all cohorts and all skill groups. These gains are closely related to a long-run fiscal gain and a small labor market impact of immigrants. Although our unit of analysis is national, we obtain small wage responses and a minor effect on income inequality. Over the last 50 years and despite the deterioration in their average education level, immigrants have significantly contributed to the American dream. Nevertheless, we also demonstrate that all generations would have benefited from a stronger selection of immigrants.

The rest of this paper is organized as follows. Section 2 describes the socio-demographic model and defines our two immigration variants. The economic model and its calibration are presented in Section 3. Simulation results are commented in Section 4. Finally, Section 5 concludes.

\section{Modelling the US population}

Our population block provides a stylized but fair representation of the US population structure per age, skill level and ethnic origin. This block is calibrated so as to match the structure of the US population between 1940 and 2000 and to generate demographic forecasts compatible with the recent projections of the Bureau of Census.

\subsection{A stylized socio-demographic representation}

We focus on the working age population and distinguish 8 cohorts of adults, from the youngest cohort (aged 15 to 24, denoted by 0 ) to the oldest cohort (aged 85 to 94, denoted by 7 ). One period thus represents 10 years. Individuals aged 0 at period $t$ are forming cohort $t$.

There are two sources of heterogeneity within each cohort:

- the first source concerns educational attainment. We distinguish low-skill, medium-skill and highskill individuals. These skill levels are denoted by the superscripts $s=l, m, h$;

- the second source refers to ethnic origin: we distinguish natives and immigrants (first generation). Immigrants are defined as individuals who were foreign-born and whose parents were non US citizen. In the spirit of Storesletten (2000), immigrants' children are considered as natives. These categories are respectively denoted by the subscripts $k=n, m$;

At time $t$, the population aged $j(j=0, \ldots, 7)$ of skill $s(s=l, m, h)$, from ethnicity $k(k=n, m)$ is denoted by $P_{k, j, t}^{s}$. For the sake of simplicity, we assume that individuals give birth to their children at 
age 30 , in the middle of their second adult period of life $^{2}$. Fifteen years after their birth, these children become new adults. Consequently, children made at time $t$ (by adults of cohort $t-1$ ) reach age 15 at time $t+2$.

Fertility differs across skill and ethnic groups. At time $t$, the number of children per individual in a specific skill and ethnic class is denoted by $n_{k, t}^{s}$. Young agents take decisions about their level of education. At time $t$, the proportions of young individuals opting for low, medium and high education are denoted by $\pi_{t}^{l}, \pi_{t}^{m}$ and $\pi_{t}^{h}$. As explained below, we consider that individuals still at school at age 18 must choose between medium and high education on the basis of the expected lifetime income associated to these educational levels ( $\pi_{t}^{m}$ and $\pi_{t}^{h}$ are endogenous). On the contrary, low-skill agents are those who stopped their schooling before age 18, i.e. before becoming independent adults. We then consider that the proportion $\pi_{t}^{l}$ is exogenous.

At each period, new immigrants are entering the country. The variable $I_{0, t}^{s}$ measures the number of young immigrants entering the US at age 0 with a skill level $s$. At each period of time, a proportion of natives and immigrants leaves the country. The variables $\xi_{n, j, t}^{s}$ and $\xi_{m, j, t}^{s}$ respectively measure net emigration rates (emigrants minus immigrants compared to the previous period population size) among natives and immigrants of skill $s$ at age $j$. These rates are positive for natives; they can be positive or negative for immigrants. Finally, some individuals die at each age. Mortality rates are allowed to vary between skill groups. We denote by $\beta_{j, t}^{s}(j=1, \ldots, 7)$ the proportion of individuals of skill $s$ dying between age $j-1$ and age $j$.

The dynamic of population is then determined by the set of 48 equations per period ( 6 equations per living cohort). The number of young natives (aged 15 to 24) of skill $s$ sums up children of natives and immigrants from generation $t-2$ (weighted by the probability to belong to the skill group $s$ ). The number of young new immigrants is exogenous. The size of young cohorts (for $s=l, m, h$ ) is modeled as follows:

$$
\begin{aligned}
& P_{n, 0, t}^{s}=\pi_{t}^{s} \sum_{s^{\prime}}\left[P_{n, 1, t-2}^{s^{\prime}} n_{n, t-2}^{s^{\prime}}+P_{m, 1, t-2}^{s^{\prime}} n_{m, t-2}^{s^{\prime}}\right] \\
& P_{m, 0, t}^{s}=I_{0, t}^{s}
\end{aligned}
$$

Regarding subsequent age cohorts, we use a simple dynamic process that take into account mortality changes, in-migration and out-migration. The sizes of cohorts aged 1 to 7 are given by (for $s=l, m, h$ and $k=n, m)$ :

$$
P_{k, j, t}^{s}=\beta_{j, t}^{s}\left(1-\xi_{k, j, t}^{s}\right) P_{k, j-1, t-1}^{s}
$$

\footnotetext{
${ }^{2}$ Rios-Rull (1992), Storesleten (2000) or Fehr and al. (2004) use a different method. They assume that agents aged $j^{\prime}$ to $j^{\prime \prime}$ (say, 23 to 45 ) give birth to fractions of children at the beginning of each period.
} 


\subsection{Identification of demographic processes}

The demographic system contains 48 equations of population size (for 8 age groups, 3 skills groups, 2 origins). In our baseline scenario, we calibrate this stylized demographic block so as to match US socio-demographic data. Between 1900 and 1930, we do not distinguish between natives and immigrants. From 1940, we explicitly model the impact of immigration ${ }^{3}$ on the population structure by age and by education. Low-skill workers are those with less than 12 years of schooling (high school dropouts). Medium-skill workers have exactly 12 years of schooling. High-skill workers have more than 12 years of schooling (some college and college graduated). Historical data on the population structure per age are obtained from the Bureau of Census. Informations about skill level and place of birth $\left(P_{n, j, t}^{s}\right.$ and $\left.P_{m, j, t}^{s} \forall j, s\right)$ are obtained from the Public Use Microdata Samples (PUMS) of the US Census and the General Social Survey (GSS).

To calibrate fertility, mortality and net emigration rates, we use the following method. The PUMS data enable to determine the shares of low, medium and high skilled among the young $\left(\bar{\pi}_{t}^{l}, \pi_{t}^{m}\right.$ and $\left.\pi_{t}^{h}\right)$. In the baseline, these shares are set to their observed values and the educational endogenous process will be calibrated so as to reproduce their historical path. Since we consider monozygotic agents, fertility rates are calibrated so as to reproduce the observed number of young at each period. Data on fertility differential between skill groups and origins $\left(n_{k, t}^{s}\right)$ are obtained from the PUMS and the GSS. Practically, we use the average number of children ever born per women in each group to fix the ratio of fertility rate compared to low-skill natives. Then, the fertility rate in this reference group $\left(n_{n, t}^{l}\right)$ is estimated so as to match the observed number of children.

Mortality rates per age and skill level $\left(\beta_{j, t}^{s}\right)$ can be computed by using life table per race (whites, blacks and others) from the National Center for Health Statistics (NCHS). We use data on the number of deaths among whites and blacks per age group between 1970 and 2000 (Data Warehouse on Trends in Health and Aging, NCHS) and data on the skill structure of whites and blacks per age group from the PUMS. We consider that the medium-skill probability to survive is a nonlinear combination of low skilled and high skilled probabilities ${ }^{4}$. This method allows us to identify the life tables for low-skill and high-skill agents (i.e. $\beta_{j, t}^{l}$ and $\beta_{j, t}^{h}$ ).

Starting from the population structure in 1940, the demographic block is then used to identify two unobserved processes, i.e. the net emigration rates of natives and immigrants $\left(\xi_{n, j, t}^{s}\right.$ and $\left.\xi_{m, j, t}^{s} \forall j, s\right)$ between 1950 and 2000. For future decades, these processes are fixed so as to reproduce the US demographic forecasts of the Bureau of Census (with a projected share of immigrants culminating at 16 percent

\footnotetext{
${ }^{3}$ We do not explicitly model the impact of illegal immigration as in Storesletten (2000).

${ }^{4}$ The log-linear process $\ln \left[\beta_{j, t}^{m}\right]=.2 \times \ln \left[\beta_{j, t}^{l}\right]+.8 \times \ln \left[\beta_{j, t}^{h}\right]$ gives a good approximation of mortality differential per race and per age.
} 
in 2050). These projections give the US structure per age and origin until 2100. The skill structure of future cohorts is estimated in the following way. For immigrants, we assume that the skill structure is stationary so that the skill structure of future immigrant cohorts gradually catches up the skill structure of the immigrant cohort aged 15-24 in 2000. The skill structure of future native cohorts is based on the high variant of Cheeseman Day and Bauman (2000). The baseline scenario then completely matches observations regarding the population structure per age, educational attainment and country of birth after 1950 .

\subsection{Counterfactual immigration variants}

Compared to the baseline, we consider two alternative immigration scenarii.

The first one ("No immigration") assumes a cutoff of all immigration flows after the year 1950. This scenario is obtained by setting $I_{0, t}^{s}$ to 0 and considers that immigrants arrived before 1950 die and leave the country as natives $\left(\xi_{m, j, t}^{s}=\xi_{n, j, t}^{s}\right.$ for $\left.j \geq 1\right)$. Eliminating all postwar immigration not only reduces the stock of immigrants but also affects the size of future cohorts of natives since immigrants' children are considered as natives. Comparing this scenario to the baseline provides an evaluation of the global impact of post-war immigration on the US economy.

The second scenario ("Selected") simulates the hypothetical situation of the US economy if past flows of immigrants had been more selective. We start from the 1940 observations. Then, between 1950 and 1960, we assume a convergence between migrants' and natives' characteristics. The number of immigrants is given in the baseline. However, the skill structure of immigrants in all age groups converges towards the skill structure of natives within two decades. Practically, we model immigrants' skill shares in all age groups as a weighted average of observed shares among immigrants and natives (the weight given to natives' shares equals .5 in 1950 and 1.0 in 1960).

The impact of these alternative scenarii is depicted in Table 1. Immigration play a crucial role in determining the size and the structure of the US population. In the "No immigration" scenario, the US population grows slowly, reaching 187.8 million in 2000 compared to 220.5 in the baseline. In 2060, the US population size is $34 \%$ lower than in the baseline scenario. The share of immigrants in the population quickly decreases and the stock of immigrants equals zero in 2030. Eliminating all postwar immigration also affects the age structure of the US population. The old age dependency ratio (the ratio of people aged 65 and over to people aged between 15 and 64) is much higher in the no immigration scenario, peaking at $36.8 \%$ in 2060 . Moreover, this scenario strongly modifies the (endogenous) skill structure of the US population, as the economic model will demonstrate.

In the "Selected scenario", the skill composition of the immigrant population is drastically affected 
but the annual net flows are unchanged. The population size, the share of immigrants in the population and the age composition is thus unaffected. On the contrary, the share of low-skill immigrants gradually declines to $8.7 \%$ in 2000 (against $28.3 \%$ in our baseline scenario) and the share of high-skill immigrants rises to $54.7 \%$ in 2000 (44\% in our baseline scenario). Since the education structure of immigrants and natives were similar before the late 1950's, the "selected scenario" gives a rough evaluation of the impact of the decline in the relative skills of immigrants related to the 1965 Amendment Act.

Table 1. US Population structure under alternative scenarii

\begin{tabular}{|c|c|c|c|c|c|c|c|c|c|c|}
\hline & & 1950 & 1960 & 1970 & 1980 & 1990 & 2000 & 2020 & 2040 & 2060 \\
\hline US Population (c) & Baseline & 109239 & 123131 & 144418 & 174546 & 194822 & 220536 & 259853 & 300591 & 342736 \\
\hline & Selective immigration (b) & $0,0 \%$ & $0,0 \%$ & $0,0 \%$ & $0,0 \%$ & $0,0 \%$ & $0,0 \%$ & $0,0 \%$ & $0,0 \%$ & $0,0 \%$ \\
\hline Population growth rate (c) & Baseline & $1,1 \%$ & $1,2 \%$ & $1,6 \%$ & $1,9 \%$ & $1,1 \%$ & $1,2 \%$ & $0,8 \%$ & $0,7 \%$ & $0,7 \%$ \\
\hline & Selective immigration (a) & $0,0 \%$ & $0,0 \%$ & $0,0 \%$ & $0,0 \%$ & $0,0 \%$ & $0,0 \%$ & $0,0 \%$ & $0,0 \%$ & $0,0 \%$ \\
\hline Share of immigrants (c) & Baseline & $9,4 \%$ & $7,5 \%$ & $6,2 \%$ & $7,2 \%$ & $9,2 \%$ & $12,1 \%$ & $14,2 \%$ & $15,7 \%$ & $15,7 \%$ \\
\hline (in \% of the population) & No Immigrati & $-0,5 \%$ & $-1,3 \%$ & $-2,5 \%$ & $-5,2 \%$ & $-8,2 \%$ & $-11,8 \%$ & $-14,2 \%$ & $-15,7 \%$ & $-15,7 \%$ \\
\hline \multirow[t]{2}{*}{ (in \% of the immigration stock) } & No I & $-1,9 \%$ & $-6,2 \%$ & $-12,8 \%$ & $-24,3 \%$ & $-30,7 \%$ & $-29,9 \%$ & $-20,4 \%$ & 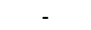 & 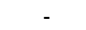 \\
\hline & Selective i & $2,6 \%$ & $3,2 \%$ & $2,0 \%$ & $2,5 \%$ & $7,9 \%$ & $10,7 \%$ & $13,3 \%$ & $17,7 \%$ & $22,1 \%$ \\
\hline \multirow{3}{*}{$\begin{array}{l}\text { Medium skilled immigrants } \\
\text { (in \% of the immigration stock) }\end{array}$} & Baseline & $15,4 \%$ & $18,0 \%$ & $24,8 \%$ & $27,8 \%$ & $27,8 \%$ & $27,7 \%$ & $27,8 \%$ & $28,0 \%$ & $28,2 \%$ \\
\hline & No In & $-4,6 \%$ & $-6,1 \%$ & $-11,0 \%$ & $-11,3 \%$ & $-6,8 \%$ & $0,4 \%$ & $3,5 \%$ & - & - \\
\hline & Selective immigration $(a, c)$ & $2,3 \%$ & $6,6 \%$ & $8,7 \%$ & $11,2 \%$ & $9,5 \%$ & $9,0 \%$ & $4,8 \%$ & $0,8 \%$ & $-1,9 \%$ \\
\hline Low skilled immigrants & Baseline & $77,4 \%$ & $70,0 \%$ & $55,6 \%$ & $39,9 \%$ & $31,1 \%$ & $28,3 \%$ & $27,0 \%$ & $26,5 \%$ & $26,5 \%$ \\
\hline (in $\%$ of the immigration stock) & No Immigration (a) & $6,5 \%$ & $12,3 \%$ & $23,9 \%$ & $35,6 \%$ & $37,4 \%$ & $29,6 \%$ & $16,9 \%$ & - & - \\
\hline
\end{tabular}

(a) Percentage points of change compared to the baseline

(b) Change in percent of the baseline

(c) Population is an endogenous variable. We report endogenous results obtained in the baseline scenario.

(d) The stock of immigrants equals zero in 2030

Source: Authors' calculations.

\section{Modelling the US economy}

To compute the economic impact of immigration, we need to depict the economic environment determining how immigrants interact with natives. This require modeling and calibrating the US technology, individual behaviors and state intervention.

\subsection{The model structure}

Technology. The production sector plays a crucial role since it defines the way immigrants compete with native workers. Instead of defining several labor markets (for low, medium and high-skill workers, for young and old workers, etc.), we assume that workers belonging to different age, skill and ethnic groups are not perfectly substitute, because they have a different "educational attainment/experience" mix. However, the stocks of education and experience are homogeneous. The interest of this approach is that the number of competing factor is independent of the number of groups considered. 
At each period of time, a representative national firm uses labor in efficiency unit $\left(Q_{t}\right)$ and physical capital $\left(K_{t}\right)$ to produce a composite good $\left(Y_{t}\right)$. We assume a Cobb-Douglas production function with constant returns to scale:

$$
Y_{t}=A_{t} K_{t}^{1-\varphi} Q_{t}^{\varphi}
$$

where $\varphi$ measures the share of wage income in the national product, and $A_{t}$ is an exogenous process representing total factor productivity.

Building on the Mincerian studies on wage determination, $Q_{t}$ explicitly aggregates the attributes of native and immigrant workers. The quantity of efficiency unit of labor combines raw labor, experience and education according to a CES nested transformation function. Formally, we have

$$
Q_{t}=\left[L_{t}^{\rho}+\mu E_{t}^{\rho}+\Theta_{t} H_{t}^{\rho}\right]^{1 / \rho}
$$

where $L_{t}$ measures the input of manpower at time $t ; E_{t}$ measures the input of experience; $H_{t}$ is the input of education; $\rho$ is the inverse of the elasticity of substitution between raw labor, experience and education and $\mu$ is a fixed parameter of preference for experience. Finally $\Theta_{t}$ is an exogenous skill biased technical progress.

The representative firm behaves competitively on the factor markets and maximizes profits:

$$
\mathrm{PROF}_{t}=Y_{t}-\left(r_{t}+d\right) K_{t}-w_{t}^{L} L_{t}-w_{t}^{H} H_{t}-w_{t}^{E} E_{t}
$$

where $d$ is the depreciation rate of physical capital.

The profit maximization by firms requires the equality of the marginal productivity of each factor to its rate of return. They may be written as

$$
\begin{aligned}
r_{t} & =(1-\varphi) A_{t} K_{t}^{-\varphi} Q_{t}^{\varphi}-d \\
w_{t}^{L} & =\varphi A_{t} K_{t}^{1-\varphi} Q_{t}^{\varphi / \rho-1} L_{t}^{\rho-1} \\
w_{t}^{E} & =\varphi A_{t} K_{t}^{1-\varphi} Q_{t}^{\varphi / \rho-1} \mu E_{t}^{\rho-1} \\
w_{t}^{H} & =\varphi A_{t} K_{t}^{1-\varphi} Q_{t}^{\varphi / \rho-1} \Theta_{t} H_{t}^{\rho-1}
\end{aligned}
$$

Clearly, the supply of experience and the supply of education influence the rates of return on these two factors:

$$
\frac{w_{t}^{H}}{w_{t}^{L}}=\left[\frac{H_{t}}{L_{t}}\right]^{\rho-1} \Theta_{t} ; \quad \frac{w_{t}^{E}}{w_{t}^{L}}=\mu\left[\frac{E_{t}}{L_{t}}\right]^{\rho-1}
$$

Skill biased technical changes $\Theta_{t}$ influence the skill premium but have no effect on the experience premium. If $\varphi / \rho<1$, a rise in the stock of education or experience reduces the basic wage level $w_{t}^{L}$. 
Preferences. Individuals have an uncertain lifetime length, i.e. a probability to die at the end of each period of life. They maximize an expected life-cycle utility function that only depends on consumption expenditures. We use a time-separable logarithmic type:

$$
E\left(U_{k, t}^{s}\right)=\sum_{j=0}^{7} \Delta_{j, t+j} \ln \left(c_{k, j, t+j}^{s}\right)
$$

where $c_{k, j, t+j}^{s}$ is the consumption of generation $t$ at age $j$ for a consumer of skill $s$ and origin $k$. The term $\Delta_{j, t+j}=\prod_{s=1}^{j} \beta_{s, t}(j=1, \ldots, 7)$ is the probability to be alive at age $j$ (evaluated at age 0 ) and such that $\Delta_{0, t+0}=1$.

As in De la Croix and Docquier (2003), we assume that each individual has the possibility to insure himself against uncertainty at the beginning of his life. Agents born at time $t$ must select the optimal consumption contingent plan that maximizes her expected utility subject to an Arrow-Debreu budget constraint and given the sequence of contingent wages and prices. For a native household $(k=n)$, the Arrow-Debreu budget constraint may be written as

$$
\begin{aligned}
& \sum_{j=0}^{7} p_{j, t+j}\left[c_{n, j, t+j}^{s}\left(1+\tau_{t+j}^{c}\right)-T_{n, j, t+j}^{s}\right] \\
= & \sum_{j=0}^{7}\left(\omega_{j, t+j}^{L}+\omega_{j, t+j}^{E} e_{n, j, t+j}^{s}+\omega_{j, t+j}^{H} h_{n, j, t+j}^{s}\right) \ell_{n, j, t+j}^{s}
\end{aligned}
$$

where $\tau_{t+j}^{c}$ is the consumption tax rate at period $t+j ; p_{j, t+j}$ is the price of one unit of good in case she is alive at age $j ; T_{k, j, t+j}^{s}$ denotes the amount of transfers received at age $j$ including education benefits, pensions and other transfers (health care, family allowances, social benefits...); $\ell_{k, j, t+j}^{s}$ measures labor supply at age $j$; raw labor, education and experience are supplied at net-of-taxes contingent wages $\omega_{j, t+j}^{L}$, $\omega_{j, t+j}^{H}$ and $\omega_{j, t+j}^{E}$. Mortality is the only source of uncertainty. Since mortality rates are assumed to differ across age and skill groups, contingent prices and wages depends on age and education.

Maximizing expected utility with respect to the levels of consumption determines the law of motion of contingent consumption expenditures over the lifetime:

$$
c_{k, j+1, t+j+1}^{s}=\frac{\left(1+r_{t+1}\right)\left(1+\tau_{t}^{c}\right)}{\left(1+\tau_{t+1}^{c}\right)} c_{k, j, t+j}^{s} \quad \forall k ; \forall s ; \forall j=0, \ldots, 6
$$


The implicit asset holdings $a_{k, j, t+j}^{s}$ of each individuals is defined as follows:

$$
\begin{aligned}
p_{0, t} a_{k, 0, t}^{s}= & \left(\omega_{0, t}^{L}+\omega_{0, t}^{E} e_{k, 0, t}^{s}+\omega_{0, t}^{H} h_{k, 0, t}^{s}\right) \ell_{k, 0, t}^{s} \\
& -p_{0, t}\left[c_{k, 0, t}^{s}\left(1+\tau_{t}^{c}\right)-T_{k, 0, t}^{s}\right] \\
p_{j, t+j} a_{j, t+j}= & p_{j-1, t+j-1} a_{k, j-1, t+j-1}^{s}+ \\
& \left(\omega_{j, t+j}^{L}+\omega_{j, t+j}^{E} e_{k, j, t+j}^{s}+\omega_{j, t+j}^{H} h_{k, j, t+s}^{s}\right) \ell_{k, j, t+j}^{s} \\
& -p_{j, t+j}\left[c_{k, j, t+j}^{s}\left(1+\tau_{t+j}^{c}\right)-T_{k, j, t+j}^{s}\right]
\end{aligned}
$$

For new immigrants entering the country with age $j^{\prime}=1 \ldots 7$ at date $t$, the budget constraint is:

$$
\begin{aligned}
& \sum_{j=j^{\prime}}^{7} p_{j, t+j-j^{\prime}}\left[c_{m, j, t+j-j^{\prime}}^{s}\left(1+\tau_{t+j-j^{\prime}}^{c}\right)-T_{m, j, t+j-j^{\prime}}^{s}\right] \\
= & p_{j^{\prime}-1, t-1}^{s} a_{m, j^{\prime}-1, t-1}^{s} \\
& +\sum_{j=j^{\prime}}^{7}\left(\omega_{j, t+j}^{L}+\omega_{j, t+j-j^{\prime}}^{E} e_{m, j, t+j-j^{\prime}}^{s}+\omega_{j, t+j-j^{\prime}}^{H} h_{m, j, t+j-j^{\prime}}^{s}\right) \ell_{m, j, t+j-j^{\prime}}^{s} .
\end{aligned}
$$

The variable $a_{m, j^{\prime}-1, t-1}^{s}$ represents the initial asset holdings of immigrants. As in Fehr and al. (2004), we assume that migrants of each generation have the same characteristics (including implicit wealth) as a native household of the same skill levels. This means that low-skill immigrants will enter the country with a small amount of wealth whilst skilled immigrants bring the same amount of wealth as skilled natives. This assumption differs from Storesletten (2000) who assumes that immigrants bring no wealth when they arrive. However, this choice seems to play a minor part on the results since nearly 70 percent of immigrants enter the country before 30, i.e. at the beginning of the wealth accumulation. Moreover, Hao (2004) demonstrates that the age-wealth profiles of immigrants and natives appear relatively similar before 35 .

The aggregated consumption at period $t$ then amounts to

$$
C_{t}=\sum_{j=0}^{7} \sum_{k=n, m} \sum_{s=l, m, h} P_{k, j, t}^{s} c_{k, j, t}^{s}
$$

Education decisions. Individual in two distinct skill groups are differentiated by the years of schooling or equivalently, by the time invested in education in the first period of their life. The exogenous variable $0 \leq \bar{u}_{s} \leq 1$ measures the proportion of time that an agent of skill $s$ must devote to education between age 15 and age 24 . One obviously has $\bar{u}_{l}<\bar{u}_{m}<\bar{u}_{h}$. Hence, each young agent selects her optimal level of schooling by comparing the monetary gain and the effort required for achieving a diploma. The monetary gain is captured by the expected lifetime labor income taken from the budget constraint:

$$
E\left(A I M E_{t}^{s}\right) \equiv \sum_{j=0}^{7}\left(\omega_{j, t+j}^{L}+\omega_{j, t+j}^{E} e_{k, j, t+j}^{s}+\omega_{j, t+j}^{H} h_{k, j, t+j}^{s}\right) \ell_{k, j, t+j}^{s}
$$


For the sake of simplicity, the effort is assumed to be proportional to the opportunity cost of education: $\lambda \omega_{0, t}^{L} \bar{u}_{s}$ where $\lambda$ is a scale variable determining the ability to educate. Young individuals are heterogenous in the sense that $\lambda$ is uniformly distributed on the segment $[\underline{\lambda}, \bar{\lambda}]$.

The proportion of individuals who stopped education before reaching a high school diploma $\left(\pi_{t}^{l}\right)$ is exogenous. This assumption relies on the fact that the decision to stop education was mainly taken at the family level. Among those who reach a high school diploma, they decide whether to pursue their education or not by comparing the gains and costs of tertiary education. The following condition defines the interval of $\lambda$ where tertiary education dominates secondary education:

$$
E\left(A I M E_{t}^{h}\right)-\lambda \omega_{0, t}^{L} \bar{u}_{h} \geq E\left(A I M E_{t}^{m}\right)-\lambda \omega_{0, t}^{L} \bar{u}_{m}
$$

This condition can be rewritten as

$$
\lambda<\lambda_{t}^{c} \equiv \frac{E\left(A I M E_{t}^{h}\right)-E\left(A I M E_{t}^{m}\right)}{\omega_{0, t}^{L}\left[\bar{u}_{h}-\bar{u}_{m}\right]}
$$

where $\lambda_{t}^{c}$ is the critical level of ability under which tertiary education dominates secondary education for the generation $t$ members.

Consequently, the proportions of agents opting for primary, secondary and tertiary education are given by

$$
\begin{aligned}
\pi_{t}^{l} & =\bar{\pi}_{t}^{l} \\
\pi_{t}^{m} & =\left(1-\bar{\pi}_{t}^{l}\right) \frac{\bar{\lambda}-\lambda_{t}^{c}}{\bar{\lambda}-\underline{\lambda}}+\varepsilon_{t} \\
\pi_{t}^{h} & =\left(1-\bar{\pi}_{t}^{l} \frac{\lambda_{t}^{c}-\underline{\lambda}}{\bar{\lambda}-\underline{\lambda}}-\varepsilon_{t}\right.
\end{aligned}
$$

where $\bar{\pi}_{t}^{l}$ is the exogenous share of low-skill workers and $\varepsilon_{t}$ is a iid. stochastic process.

Human capital. The proportion of individual belonging to group $s$ is fully determined by education decisions presented above. The time invested in education influences labor supply, education-related human capital and the accumulation of experience.

The vector of labor supply for an agent of generation $t$ (defining labor supply at all ages) is

$$
\bar{\ell}_{k, t}^{s}=\left(q_{t}\left(1-\bar{u}_{s}\right), q_{t+1}, q_{t+2}, q_{t+3}, q_{t+4}\left(1-\alpha_{t+4}\right), 0,0,0\right)
$$

where $q_{t}$ is the exogenous activity rate at time $t$ and $\alpha_{t+4}$ stands for the (exogenous) time spent in retirement in the fifth period of life (i.e. between age 55 and age 64). The variable $q_{t}$ essentially captures the rise in women's participation rates on the labor market.

As in Wasmer (2001b), the individual stock of experience, $\bar{e}_{k, t}^{s}$, sums up past participation rates on the labor market. The stock of education, $\bar{h}_{k, t}^{s}$, transforms education investment when young into labor 
efficiency according to a decreasing return function. These vectors are written as

$$
\begin{aligned}
\bar{e}_{k, t}^{s}= & \left(0,\left(1-\bar{u}_{s}\right) q_{t} \theta_{e}^{1},\left(1-\bar{u}_{s}\right) q_{t} \theta_{e}^{2}+q_{t+1} \theta_{e}^{1},\left(1-\bar{u}_{s}\right) q_{t} \theta_{e}^{3}+q_{t+1} \theta_{e}^{2}+q_{t+2} \theta_{e}^{1},\right. \\
& \left.\left(1-\bar{u}_{s}\right) q_{t} \theta_{e}^{4}+q_{t+1} \theta_{e}^{3}+q_{t+2} \theta_{e}^{2}+q_{t+3} \theta_{e}^{1}, 0,0,0\right),
\end{aligned}
$$

where $\theta_{e}^{j} \in(0,1)$ represents one minus the depreciation of experience over the lifetime;

$$
\bar{h}_{k, t}^{s}=\left(0, \epsilon \bar{u}_{s}^{\psi}, \epsilon \bar{u}_{s}^{\psi}, \epsilon \bar{u}_{s}^{\psi}, \epsilon \bar{u}_{s}^{\psi}, 0,0,0\right),
$$

where $\epsilon>0$ and $\psi \in(0,1)$ are two parameters of the educational technology.

We disregard assimilation issues and consider that experience and education accumulated abroad are equivalent to experience and education accumulated in the domestic economy. The aggregate quantity for raw labor $\left(L_{t}\right)$, experience $\left(E_{t}\right)$ and education $\left(H_{t}\right)$ are

$$
\begin{aligned}
L_{t} & =\sum_{j=0}^{7} \sum_{k=n, m} \sum_{s=l, m, h} P_{k, j, t}^{s} \ell_{k, j, t}^{s} \\
E_{t} & =\sum_{j=0}^{7} \sum_{k=n, m} \sum_{s=l, m, h} P_{k, j, t}^{s} \ell_{k, j, t}^{s} e_{k, j, t}^{s} \\
H_{t} & =\sum_{j=0}^{7} \sum_{k=n, m} \sum_{s=l, m, h} P_{k, j, t}^{s} \ell_{k, j, t}^{s} h_{k, j, t}^{s}
\end{aligned}
$$

The public sector. Public transfers sum up education subsidies, pension benefits and other transfers. The vector of transfers can be written as

$$
\begin{aligned}
\bar{T}_{k, t}^{s}= & \left(v_{t} q_{t} \bar{u}_{s} \omega_{0, t}^{L}+\gamma_{k, 0}^{s} g_{t}, \gamma_{k, 1}^{s} g_{t+1}, \gamma_{k, 2}^{s} g_{t+2}, \gamma_{k, 3}^{s} g_{t+3},\right. \\
& \alpha_{t+4} b_{k, 4, t+4}^{s}+\gamma_{k, 4}^{s} g_{t+4}, b_{k, 5, t+5}^{s}+\gamma_{k, 5}^{s} g_{t+5}, \\
& \left.b_{k, 6, t+6}^{s}+\gamma_{k, 6}^{s} g_{t+6}, b_{k, 7, t+7}^{s}+\gamma_{k, 7}^{s} g_{t+7}\right)
\end{aligned}
$$

where $v_{t}$ is the rate of subsidy on the cost of education and $\gamma_{k, j}^{s} g_{t}$ is the amount of age-related transfers made by the government to agents of age $j$, skill $s$ and ethnicity $k$. The parameters $\gamma_{k, j}^{s}$ describe the transfers profile per age, skill and ethnicity; $g_{t}$ is a scale variable capturing the generosity of welfare programs. The endogenous variable $b_{k, j, t+j}^{s}$ measures pension benefits allocated to each full-time retiree from generation $t$ at period $t+j(j=4$ to 7$)$ and $\alpha_{t+4}$ the old age participation rate. For simplicity, pension benefits are proportional to the last period hourly earnings. We write

$$
b_{k, j, t+j}^{s}=\eta_{t} \eta_{k}\left[\omega_{4, t+4}^{L}+\omega_{4, t+4}^{E} e_{k, 4, t+4}^{s}+\omega_{4, t+4}^{H} h_{k, 4, t+4}^{s}\right] \quad(j=4, \ldots, 7)
$$

where $\eta_{t}$ is a deterministic exogenous process capturing the generosity of the social security system, $\eta_{k}$ is a pair of parameters capturing the relative pension of immigrants compared to natives $\left(\eta_{n}\right.$ is normalized to unity). 
The government issues bonds and levies taxes on labor earnings $\left(\tau_{t}^{w}\right)$, consumption expenditures $\left(\tau_{t}^{c}\right)$ and capital income $\left(\tau_{t}^{k}\right)$ to finance public transfers and general public consumption. Five types of spending are distinguished: education subsidies, social security benefits, other transfers (health care, family allowance, social benefits), non-age-specific general consumption and the interest on public debt. The government budget constraint may be written as

$$
\begin{aligned}
& \tau_{t}^{w}\left(w_{t}^{L} L_{t}+w_{t}^{E} E_{t}+w_{t}^{H} H_{t}\right)+\tau_{t}^{c} C_{t}+\tau_{t}^{k} r_{t} K_{t}+D_{t+1} \\
= & \sum_{j} \sum_{k} \sum_{s} P_{k, j, t}^{s} T_{k, j, t}^{s}+\vartheta_{t} Y_{t}+\left(1+r_{t}\right) D_{t}
\end{aligned}
$$

where $D_{t}$ denotes the public debt at the beginning of period $t ; \vartheta_{t}$ is the share of non-transfer public consumption in GDP and $T_{k, j, t}^{s}$ is the amount of transfers per capita defined above.

Several scenarii can be considered to balance this budget constraint. The budget can be balanced through tax adjustments, expenditure adjustments or changes in the public debt. We assume in the sequel that the path of debt is given and the tax rate on consumption $\tau_{t}^{c}$ adjusts to balance the budget.

Competitive equilibrium. At each date, the composite good is taken as numeraire. The spot price is thus normalized to one: $p_{t}=1$. We write $r_{t+1}$ the interest rate between the dates $t$ and $t+1$, the appropriate discount factor applied to age- $j$ income and spending is given by

$$
R_{j, t+j} \equiv \prod_{s=t+1}^{t+j}\left(1+r_{s}\left(1-\tau_{s}^{k}\right)\right)^{-1}
$$

where, by convention, $R_{0, t}=1$. Spot gross wages at time $t+j$ are denoted by $w_{t+j}^{L}, w_{t+j}^{H}$ and $w_{t+j}^{E}$. They correspond to the marginal productivities of labor components, as shown below. Since there is perfect competition on the insurance market, the contingent prices are related to the spot prices through a set of no arbitrage conditions. The equilibrium (discounted) contingent prices of the consumption good and net wages at time $t$ are given by:

$$
\begin{aligned}
p_{j, t+j} & =R_{j, t+j} \Delta_{j, t+j} p_{t+j}=R_{j, t+j} \Delta_{j, t+j} \\
\omega_{j, t+j}^{L} & =R_{j, t+j} \Delta_{j, t+j} w_{t+j}^{L}\left(1-\tau_{t+j}^{w}\right) \\
\omega_{j, t+j}^{E} & =R_{j, t+j} \Delta_{j, t+j} w_{t+j}^{E}\left(1-\tau_{t+j}^{w}\right) \\
\omega_{j, t+j}^{H} & =R_{j, t+j} \Delta_{j, t+j} w_{t+j}^{H}\left(1-\tau_{t+j}^{w}\right)
\end{aligned}
$$

A competitive equilibrium is obtained when all individuals maximize their expected utility subject to the budget constraint, the representative firm maximizes profits subject to the technology, the government budget constraint is balanced, contingent prices and wages are such that the no arbitrage conditions hold and spot prices and wages are such that the goods and labor markets are in equilibrium. 


\subsection{Calibration of the baseline}

Calibration implies using data for observed exogenous variables, fixing some constant parameters, and choosing paths for the unobserved exogenous variables (exogenous variables for which time series data are not available) in order to match a series of characteristics.

Regarding observed exogenous processes, the old age participation rate $\alpha$ is computed using the effective retirement age data from Blondal and Scarpetta (1997). Overall participation rates $q_{t}$ are normalized to 1 in 2000 and computed from Wasmer (2001b). As for public finance, three proportional taxes are introduced in our model, the labor income tax, the capital income tax and indirect taxes. The tax rates are calibrated in such a way that the shares of revenues in GDP correspond to the estimations of Gokhale and al. (1999), i.e. $8 \%$ for labor income, $7 \%$ for indirect taxes and 5\% for capital income in 2000. The history of tax rates reproduces the evolution of fiscal receipts in percent of GDP. Between 1900 and 2000, the public debt/GDP ratio is exogenously set to its observed value. Observations are taken from OECD statistics for the period 1985-2000. For previous periods, we use data from Brown (1990). We distinguish two types of government spending (net of debt charges), i.e. non age-specific public consumption and age-specific transfers ${ }^{5}$. For the composition of these categories, we build on Gokhale and al. (1999). The history of non age-specific spending is based on OECD data for the period 1960-1995. For age-specific transfers, we calibrate age profiles per age, education and country of birth. Profiles per education level are taken from Lee and Miller (1997). Differences between natives and immigrants are taken from Auerbach and Oreopoulos (2000). Within each age category, education and origin scaling factors multiply an age component. The latter is calibrated in such a way that the average level of transfers in the age class matches the estimates of Gokhale and al. (1999). We assume that the resulting age profiles are constant over time but are rescaled (through changes in $g_{t}$ ) so as to match the share of social transfers in GDP. Social security benefits depend on the hourly earnings in the last working period: the scale process $\eta_{t}$ is fixed so as to match the share of social security benefits in GDP. Finally, the rate of subsidy on tertiary education expenditures, $v_{t}$, is taken from De la Croix and Docquier (2003).

Regarding parameters, we use common values for calibrated models of the US economy. The labor share in output, $\varphi$, is set to .7. The depreciation rate of capital $d$ equals .4. This value implies an annual depreciation rate of $5 \%$. The depreciation rate of experience follows the median hypothesis of Wasmer (2001b), i.e. an annual rate of $3 \%$, independent of age. This yields $\theta_{e}^{1}=0.737, \theta_{e}^{2}=\left(\theta_{e}^{1}\right)^{2}$ etc... The parameter $\mu$ in the production function is a scale parameter of no importance given the later choice of $\Theta_{t}$; it is set to .5. The parameter $\psi$ is the elasticity of education capital to investment in education. It

\footnotetext{
${ }^{5}$ Including medicare, medicaid, unemployment, AFDC, food stamps and general welfare.
} 
determines the concavity of the relationship between income and education. Using $\psi=0.75$, we fairly reproduce income differentials between low, medium and high-skill workers. The scale parameter in the production function of human capital $\epsilon$ is set to 1.2 so as to deliver an adequate wage profile. The parameter $\eta_{m}$ measuring the relative pension of immigrants compared to the rest of the population is set to .907 . Such a ratio is compatible with the generational accounting data of Auerbach and Oreopoulos (2000). The parameter $\rho$ determines substitution between raw labor, education and experience. In the baseline, we use $\rho=.7$, implying an elasticity of substitution $(1 /(1-\rho))$ of 3.33 . This baseline value corresponds to the elasticity of substitution between unskilled and skilled labor in classical production functions. Since we use a different type of technology, we provide a sensitivity analysis to this parameter by setting $\rho=.5$ and $\rho=.9$ in the appendix. Finally, the lower and upper bounds of the ability distribution must be calibrated to match the evolution of educational attainment in the United States. We estimate these parameters by a standard OLS regression. This gives $\underline{\lambda}=-1.54$ and $\bar{\lambda}=9.09$. As shown on figure 1, this distribution provides an accurate prediction of the rise in educational attainment between 1900 and 2100. The iid deviation process $\varepsilon_{t}$ is identified as the difference between observations and simulated values at the baseline. This identified process is used as exogenous in the alternative scenarii.

Figure 1: Proportion of students opting for tertiary education

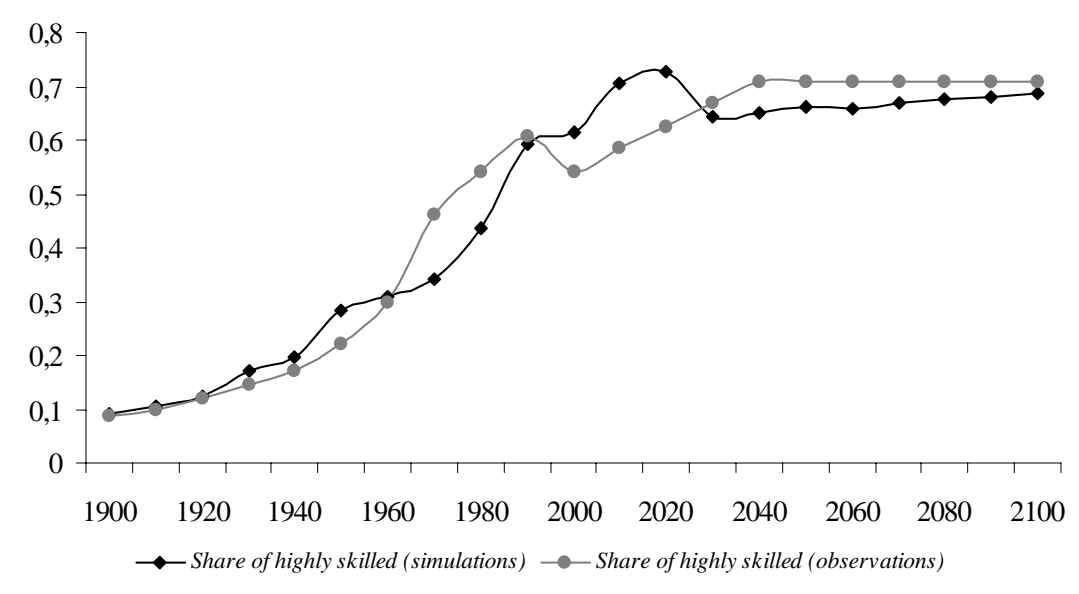

Regarding unobserved exogenous processes, our methodology follows two steps. In the baseline scenario (matching the US historical time path), we use the model to identify four unobserved exogenous variables: total factor productivity, $A_{t}$, the skill-biased technical progress, $\Theta_{t}$, the scale process of social security benefit, $\eta_{t}$, and the scale of the age-specific transfers profile, $g_{t}$. These four exogenous processes are chosen so as to match available time series data for four closely related endogenous variables: the 
GDP growth rate, the share of social security and other transfers in GDP and the wage gap between high-skill and low-skill workers at age $45^{6}$. Basically, our identification methodology implies swapping four exogenous variables for four endogenous variables. This resembles Sims (1990) backsolving approach for stochastic general equilibrium models. We use a similar idea of treating exogenous processes as endogenous, not to solve a model, but as a calibration device in a deterministic framework. This procedure allows to calibrate the model "dynamically". This is much better and rigorous than calibrating on a hypothetical steady state (in 1900 or in 2250) and then scaling exogenous variables to obtain reasonable outcomes at a given date, as it is usually done in computable general equilibrium tradition. Hence, in the baseline scenario, the GDP growth rate, the wage gap, the shares of social security benefits and the share of other transfers in GDP will be exactly matched by the model.

Given the backsolving approach, the baseline scenario exactly matches the major "first-order" processes of the US economy. The quality of our model also depends on its ability to reproduce the distribution characteristics ("second-order moments"). We focus on wages of natives aged 25 to 65 and calculate the Gini index and percentile wage differentials. The Gini index summarizes the shape of the entire earnings distribution in a single statistic. As shown in table 2, the baseline scenario gives an accurate vision of the evolution of the wage structure compared to Census data. Between 1950 and 2000 , the Gini index rose from 0.132 to 0.198 (an increase of 50\%) peaking at about 0.20 in 1990 . Nevertheless, the Gini index is less revealing about the structure of earnings than a series of ratios of selected percentile cutoffs (P90/P10, P90/P50 and P50/P10). A useful comparison of what has happened to the upper and lower portions of the wage distribution is provided by examining changes in the P90/P50 and P50/P10 ratios. The percentile differentials approach shows a similar rise in inequality, the P90/P10 census ratio rose from 1.98 to $2.64(+33 \%)$ with a maximum at 2.85 in 1980 . However, this trend is due to a pattern of wage growth in which the P50/P10 ratio accelerates $(+36 \%)$ and the P90/P50 ratio decreases $(-2.2 \%)$. Table 2 also illustrates some variations over time in the magnitude and timing of changes in wage inequality. The baseline of our model slightly overstates this global pattern with an $41 \%$ increase in the $\mathrm{P} 90 / \mathrm{P} 10$ ratio, $46 \%$ in the $\mathrm{P} 50 / \mathrm{P} 10$ ratio and a $3 \%$ decrease in the $\mathrm{P} 90 / \mathrm{P} 50$ ratio.

Table 2. Index of wage inequality - baseline results and observations (1950-2000)

\begin{tabular}{|c|c|c|c|c|c|c|c|}
\hline & & 1950 & 1960 & 1970 & 1980 & 1990 & 2000 \\
\hline Gini Index & Census & 0,1324 & 0,1542 & 0,1736 & 0,1819 & 0,2064 & 0,1975 \\
\hline (based on natives' net wages) & Baseline & 0,1325 & 0,1570 & 0,1890 & 0,1835 & 0,2018 & 0,1989 \\
\hline P90/P10 & Census & 1,983 & 2,151 & 2,797 & 2,853 & 2,628 & 2,638 \\
\hline (ratio of percentiles) & Baseline & 1,967 & 1,982 & 2,632 & 2,632 & 2,914 & 2,788 \\
\hline P90/P50 & Census & 1,444 & 1,546 & 1,929 & 1,634 & 1,289 & 1,412 \\
\hline (ratio of percentiles) & Baseline & 1,561 & 1,541 & 1,785 & 1,636 & 1,256 & 1,515 \\
\hline P50/P10 & Census & 1,374 & 1,391 & 1,450 & 1,746 & 2,039 & 1,868 \\
\hline (ratio of percentiles) & Baseline & 1,260 & 1,286 & 1,475 & 1,609 & 2,320 & 1,840 \\
\hline
\end{tabular}
Source: IPUMS; Authors' calculations.

\footnotetext{
${ }^{6}$ The actual wage gap is computed from Census data.
} 


\section{Immigration, inequality and welfare}

Our calibrated model can be used to compute the consequences of the US postwar immigration. We simulate the impact of the two counterfactual immigration variants on the US economy. Table 3 gives the results in deviation of the baseline. We mainly concentrate on the "no immigration" variant which eliminates all postwar immigration flows. The "selected" variant is commented at the end of the section.

Table 3. Economic consequences of the US immigration

\begin{tabular}{|c|c|c|c|c|c|c|c|c|c|c|}
\hline & & 1950 & 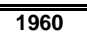 & 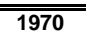 & 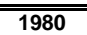 & 1990 & 2000 & 2020 & $\overline{2040}$ & 2060 \\
\hline Tax rate on consumption & Baseline & $9,5 \%$ & $10,0 \%$ & $11,0 \%$ & $12,0 \%$ & $13,0 \%$ & $14,0 \%$ & $16,0 \%$ & $16,5 \%$ & $12,5 \%$ \\
\hline \multirow[t]{2}{*}{ (in \%) } & No Immigration (a) & $0,2 \%$ & $0,5 \%$ & $0,8 \%$ & $0,7 \%$ & $0,4 \%$ & $1,1 \%$ & $1,3 \%$ & $1,5 \%$ & $1,0 \%$ \\
\hline & Selective immigration (a) & $-0,1 \%$ & $-0,1 \%$ & $0,0 \%$ & $0,0 \%$ & $-0,3 \%$ & $-0,8 \%$ & $-0,9 \%$ & $-1,0 \%$ & $-0,9 \%$ \\
\hline Public transfers & Baseline & $8,0 \%$ & $9,5 \%$ & $12,0 \%$ & $13,0 \%$ & $13,2 \%$ & $13,6 \%$ & $15,0 \%$ & $15,4 \%$ & $13,7 \%$ \\
\hline \multirow[t]{2}{*}{ (in \% of GDP) } & No Immigration (a) & $0,1 \%$ & $0,2 \%$ & $0,3 \%$ & $0,4 \%$ & $0,3 \%$ & $0,3 \%$ & $0,4 \%$ & $0,6 \%$ & $0,4 \%$ \\
\hline & Selective immigration (a) & $0,0 \%$ & $0,0 \%$ & $0,0 \%$ & $0,0 \%$ & $-0,1 \%$ & $-0,3 \%$ & $-0,5 \%$ & $-0,5 \%$ & $-0,5 \%$ \\
\hline Average human capital per worker & Baseline & 1,000 & 1,244 & 1,559 & 2,117 & 2,810 & 3,016 & 3,136 & 3,280 & 3,376 \\
\hline \multirow{2}{*}{$(H / L)$} & No Immigration (b) & $-0,8 \%$ & $-0,4 \%$ & $0,1 \%$ & $1,4 \%$ & $2,8 \%$ & $4,3 \%$ & $5,0 \%$ & $5,8 \%$ & $6,3 \%$ \\
\hline & Selective immigration (b) & $1,4 \%$ & $0,9 \%$ & $0,4 \%$ & $0,7 \%$ & $1,7 \%$ & $2,8 \%$ & $3,8 \%$ & $4,6 \%$ & $4,8 \%$ \\
\hline Average experience per worker & Baseline & 1,000 & 1,028 & 0,996 & 0,933 & 0,964 & 1,071 & 1,170 & 1,154 & 1,143 \\
\hline \multirow[t]{2}{*}{$(E / L)$} & No Immigration (b) & $0,2 \%$ & $0,4 \%$ & $0,4 \%$ & $1,1 \%$ & $1,4 \%$ & $1,9 \%$ & $0,5 \%$ & $-0,2 \%$ & $-0,2 \%$ \\
\hline & Selective immigration (b) & $-0,1 \%$ & $-0,1 \%$ & $0,0 \%$ & $0,0 \%$ & $-0,2 \%$ & $-0,6 \%$ & $-0,9 \%$ & $-1,0 \%$ & $-1,1 \%$ \\
\hline Skill premium & Baseline & $66,5 \%$ & $78,0 \%$ & $99,9 \%$ & $106,0 \%$ & $160,7 \%$ & $184,8 \%$ & $178,7 \%$ & $179,7 \%$ & $179,9 \%$ \\
\hline \multirow[t]{2}{*}{ (secondary school - in \%) } & No Immigration (a) & $0,2 \%$ & $0,1 \%$ & $0,0 \%$ & $-0,4 \%$ & $-1,3 \%$ & $-2,3 \%$ & $-2,6 \%$ & $-3,0 \%$ & $-3,3 \%$ \\
\hline & Selective immigration (a) & $-0,3 \%$ & $-0,2 \%$ & $-0,1 \%$ & $-0,2 \%$ & $-0,8 \%$ & $-1,5 \%$ & $-2,0 \%$ & $-2,4 \%$ & $-2,5 \%$ \\
\hline Experience premium & Baseline & $54,4 \%$ & $53,9 \%$ & $54,4 \%$ & $55,5 \%$ & $55,0 \%$ & $53,3 \%$ & $51,9 \%$ & $52,1 \%$ & $52,2 \%$ \\
\hline \multirow[t]{2}{*}{ (20 years of experience - in \%) } & No Immigration (a) & $0,0 \%$ & $-0,1 \%$ & $-0,1 \%$ & $-0,2 \%$ & $-0,2 \%$ & $-0,3 \%$ & $-0,1 \%$ & $0,0 \%$ & $0,0 \%$ \\
\hline & Selective immigration (a) & $0,0 \%$ & $0,0 \%$ & $0,0 \%$ & $0,0 \%$ & $0,0 \%$ & $0,1 \%$ & $0,1 \%$ & $0,2 \%$ & $0,2 \%$ \\
\hline Wage gap at age 45 & Baseline & 1,881 & 2,056 & 2,374 & 2,440 & 3,186 & 3,489 & 3,392 & 3,400 & 3,401 \\
\hline \multirow{2}{*}{ (high skilled / low skilled) } & No Immigration (b) & $0,1 \%$ & $0,1 \%$ & $0,0 \%$ & $-0,2 \%$ & $-0,5 \%$ & $-0,8 \%$ & $-1,0 \%$ & $-1,2 \%$ & $-1,3 \%$ \\
\hline & Selective immigration (b) & $-0,2 \%$ & $-0,2 \%$ & $-0,1 \%$ & $-0,1 \%$ & $-0,4 \%$ & $-0,7 \%$ & $-0,9 \%$ & $-1,1 \%$ & $-1,1 \%$ \\
\hline Return on capital & Baseline & $5,7 \%$ & $3,7 \%$ & $4,2 \%$ & $7,5 \%$ & $7,1 \%$ & $1,0 \%$ & $1,7 \%$ & $3,0 \%$ & $3,4 \%$ \\
\hline \multirow{2}{*}{ (annual real interest rate in \%) } & No Immigration (a) & $0,0 \%$ & $0,0 \%$ & $-0,1 \%$ & $0,0 \%$ & $-0,1 \%$ & $-0,1 \%$ & $-0,1 \%$ & $-0,1 \%$ & $-0,1 \%$ \\
\hline & Selective immigration (a) & $0,0 \%$ & $0,0 \%$ & $0,0 \%$ & $0,0 \%$ & $0,0 \%$ & $0,0 \%$ & $0,0 \%$ & $0,0 \%$ & $0,0 \%$ \\
\hline GDP per capita & Baseline & 1,000 & 1,000 & 1,000 & 1,000 & 1,000 & 1,000 & 1,000 & 1,000 & 1,000 \\
\hline \multirow[t]{2}{*}{ (Baseline = 1.000) } & No Immigration (b) & $-0,5 \%$ & $-0,9 \%$ & $-0,7 \%$ & $-0,9 \%$ & $0,8 \%$ & $1,5 \%$ & $1,3 \%$ & $0,7 \%$ & $1,4 \%$ \\
\hline & Selective immigration (b) & $0,7 \%$ & $1,2 \%$ & $1,0 \%$ & $1,2 \%$ & $-0,1 \%$ & $-0,1 \%$ & $0,6 \%$ & $1,7 \%$ & $1,3 \%$ \\
\hline Gini Index & Baseline & 0,132 & 0,157 & 0,189 & 0,184 & 0,202 & 0,199 & 0,193 & 0,177 & 0,166 \\
\hline \multirow{2}{*}{ (based on natives' net wages) } & No Immigration (b) & $0,31 \%$ & $0,26 \%$ & $0,10 \%$ & $-0,17 \%$ & $-0,78 \%$ & $-1,23 \%$ & $-1,03 \%$ & $-0,59 \%$ & $-0,87 \%$ \\
\hline & Selective immigration (b) & $-0,35 \%$ & $-0,22 \%$ & $-0,08 \%$ & $-0,13 \%$ & $-0,10 \%$ & $-0,02 \%$ & $0,16 \%$ & $0,49 \%$ & $0,68 \%$ \\
\hline P90/P10 & Baseline & 1,967 & 1,982 & 2,632 & 2,632 & 2,914 & 2,788 & 2,681 & 2,614 & 2,567 \\
\hline \multirow[t]{2}{*}{ (ratio of percentiles) } & No Immigration (b) & $0,14 \%$ & $0,12 \%$ & $0,03 \%$ & $-0,15 \%$ & $-0,46 \%$ & $-0,28 \%$ & $-0,40 \%$ & $-0,50 \%$ & $-0,54 \%$ \\
\hline & Selective immigration (b) & $-0,24 \%$ & $-0,18 \%$ & $-0,07 \%$ & $-0,13 \%$ & $-0,37 \%$ & $-0,26 \%$ & $-0,36 \%$ & $-0,44 \%$ & $-0,46 \%$ \\
\hline P90/P50 & Baseline & 1,561 & 1,541 & 1,785 & 1,636 & 1,256 & 1,515 & 1,357 & 1,101 & 1,101 \\
\hline \multirow[t]{2}{*}{ (ratio of percentiles) } & No Immigration (b) & $0,16 \%$ & $0,05 \%$ & $0,00 \%$ & $-0,08 \%$ & $-0,01 \%$ & $-0,01 \%$ & $0,02 \%$ & $0,13 \%$ & $0,14 \%$ \\
\hline & Selective immigration (b) & $-0,24 \%$ & $-0,09 \%$ & $-0,03 \%$ & $-0,06 \%$ & $-0,03 \%$ & $-0,02 \%$ & $0,01 \%$ & $0,13 \%$ & $0,13 \%$ \\
\hline P50/P10 & Baseline & 1,260 & 1,286 & 1,475 & 1,609 & 2,320 & 1,840 & 2,013 & 2,375 & 2,332 \\
\hline \multirow[t]{2}{*}{ (ratio of percentiles) } & No Immigration (b) & $-0,01 \%$ & $0,07 \%$ & $0,03 \%$ & $-0,07 \%$ & $-0,44 \%$ & $-0,27 \%$ & $-0,44 \%$ & $-0,63 \%$ & $-0,68 \%$ \\
\hline & Selective immigration (b) & $0,00 \%$ & $-0,09 \%$ & $-0,04 \%$ & $-0,07 \%$ & $-0,35 \%$ & $-0,24 \%$ & $-0,39 \%$ & $-0,56 \%$ & $-0,59 \%$ \\
\hline
\end{tabular}

Impact on the labor market. The economic consequences of immigration are closely related to labor market changes. In the literature, most attention has been paid to three explanations for rising wage inequality : demand, supply and institutional factors. Demand factors include factor-biased technical change, trade with low-wage countries, decline of manufacturing and rise of service jobs. Supply factors determine the available quantity and quality of different types of workers: changes in educational attainment, immigration, in natives' cohort sizes, labor force participation rates by sex and age group. Some studies have focused on the changes in labor market institutions: extent of unionization in the economy and the level of the minimum wage. In our framework, we disregard institutional factors 
but capture demand factors (through skill biased technical changes) as well as supply factors (through a complex population block). Although the technical change favoring high-skill workers is the main force toward rising inequality, the model determines whether changes in immigration policy mitigate or exacerbate the changes.

Our simulation reveal that the postwar immigration has reduced the stock of human capital per worker after the 1965 Amendments to the Immigration and Nationality Act. Since immigrants are less educated than natives, the average level of education increases in the "no immigration" variant by 4.3 percent in 2000 and 6.3 percent in 2060. Since immigrants are younger than natives, the average level of experience per worker also increases until 2020. Consequently, the skill premium (-2.3 percent in 2000) and the experience premium (-0.3 percent in 2000) are lower in the variant. These trends correspond to intuition but their magnitude differs from recent studies in two major respects:

- first, immigration has a small impact on the labor market outcomes. According to our simulations, a 10 percent increase in immigration reduces the average wage of natives by 1 percent. Although our unit of analysis is the national level, such a magnitude is comparable to that obtained in spatial correlation studies (see Friedberg and Hunt, 1995) and 3 or 4 times lower than that obtained by Borjas (2003);

- second, all skill groups are equivalently affected by immigration. On average, the wage response to a 10 percent increase in immigration amounts to -1.3 percent for low-skill workers, -1.2 percent for medium-skill and -0.9 percent for high-skill workers. Given a stronger complementarity with immigrants, the highly skilled suffer less from immigration. However the differences with the less educated workers are small. Hence, contrary to expectations, the redistributive impact of immigration is quite small in our analysis. This is clearly shown in table 3 where immigration increases by only 0.8 percent the wage ratio between a college graduate and a high school dropout at age 45 in 2000. Demand factors and the natives supply of skills explain most of the drastic changes in the wage distribution over the last 50 years.

How can we explain such differences with the partial equilibrium studies by Borjas, Freeman and $\mathrm{Katz}^{7}$ (1997) and Borjas (2003)? These studies use the aggregate "factor proportions approach" to estimate the impact of immigration and trade on the U.S. labor market. They found that immigration has had a marked adverse impact on the economic status of the least skilled U.S. workers. Whereas immigration and LDC trade have modest impacts on the college-high school wage differential from 1980 to 1995, the effect of post-1979 immigrants on relative skill supplies explain between 27 to 55 percent of the actual

\footnotetext{
${ }^{7}$ Henceforth, BFK.
} 
decline in the relative wages of high school dropouts over 1980-95 (depending on the wage elasticity chosen). Although general equilibrium provides additional insights compared to partial equilibrium, the major difference resides in the way the demand side of the labor market is modeled. Basically, the BFK approach relies on CES aggregate production function $F\left(L^{s}, L^{u}\right)$ with two inputs (skilled labor, $L^{s}$, and unskilled labor, $L^{u}$ ) and an inelastic short-run relative labor supply function. The partial equilibrium approach then yields the following relationship between relative wages and relative labor supplies:

$$
\ln \frac{W_{t}^{s}}{W_{t}^{u}}=(1-\rho)\left(D_{t}-\ln \frac{L_{t}^{s}}{L_{t}^{u}}\right)
$$

with $1 /(1-\rho)$ the elasticity of substitution between skilled and unskilled workers and $D_{t}$ stands for the $\log$ of relative demand shifts for skilled workers.

Denoting by $L_{n, t}^{i}$ and $L_{m, t}^{i}$ the labor supply of skill $i=s, u$ of natives and immigrants, the national supply of skill group $i$ at time $t$ can be written as:

$$
L_{t}^{i}=L_{n, t}^{i}+L_{m, t}^{i}
$$

We have

$$
\ln \frac{L_{t}^{s}}{L_{t}^{u}}=\ln \frac{L_{n, t}^{s}}{L_{n, t}^{u}}+\ln \left(1+\frac{L_{m, t}^{s}}{L_{n, t}^{s}}\right)-\ln \left(1+\frac{L_{m, t}^{u}}{L_{n, t}^{u}}\right)
$$

so that the contribution of immigration $\left(I M C_{t}\right)$ to the log of relative wages is given, in the BFK approach, by:

$$
I M C_{t}=(1-\rho)\left[\ln \left(1+\frac{L_{m, t}^{s}}{L_{n, t}^{s}}\right)-\ln \left(1+\frac{L_{m, t}^{u}}{L_{n, t}^{u}}\right)\right]
$$

Applying such a "factor proportion" technique to our population data and using $\rho=.7$, the post-1940 immigration accounts for 33 percent of the 0,313 log point increase in wage differential between mediumskill and low-skill workers from 1940 to 2000 . As shown in table 4, such a contribution falls to 11 percent with $\rho=.9$ and rises to 55 percent with $\rho=.5$. The range of the immigration contribution is thus fully compatible with BFK results. 
Table 4. Estimated contribution of immigration to wage differentials (a), 1940-2000

\begin{tabular}{|c|c|c|c|c|}
\hline \multirow{2}{*}{ Elasticity of substitution beween factors } & & \multicolumn{3}{|c|}{ Medium versus low skilled } \\
\hline & & & & \\
\hline Parameter & $\rho$ & 0,9 & 0,7 & 0,5 \\
\hline Elasticity of wage differential & $\rho-1$ & $-0,1$ & $-0,3$ & $-0,5$ \\
\hline Elasticity of substitution & $1 /(1-\rho)$ & 10,0 & 3,3 & 2,0 \\
\hline Actual change (b) & & 0,313 & 0,313 & 0,313 \\
\hline \multicolumn{5}{|l|}{ Estimated contribution of immigration } \\
\hline Prod. Function with skilled and unskilled labor (BFK) & Impact on the wage ratio & 0,0344 & 0,1032 & 0,1721 \\
\hline Prod. Function with raw labor and education & Impact on the return to schooling & 0,0064 & 0,0192 & 0,0321 \\
\hline \multicolumn{5}{|l|}{ Percent contribution (c ) } \\
\hline Prod. Function with skilled and unskilled labor (BFK) & Impact on the wage ratio & 11 & 33 & 55 \\
\hline Prod. Function with raw labor and education & Impact on the return to schooling & 2 & 6 & 10 \\
\hline Our method (general equilibrium - 3 inputs) & Impact on the wage ratio & $-0,7$ & 0,5 & 1,5 \\
\hline
\end{tabular}

Our method (general equilibrium - 3 inputs)

(a) Log point, except as indicated

(b) Actual changes in log wages differentials are calculated from Census data. They are expressed in log points.

(c) Log point contribution as percentage of actual log point change, 1940-2000.

Source: Authors' calculations.

Our production function builds on the microeconometric wage equation (a la Mincer) and distinguishes three major wage components: raw labor, experience and education. To simplify the exposition, let us temporarily disregard experience. Compared to BFK, we consider an aggregate production function $F(L, H)$ with two inputs (raw labor, $L$, and education, $H$ ). The return to schooling is then given by:

$$
\ln \frac{W_{t}^{H}}{W_{t}^{L}}=(1-\rho)\left(D_{t}-\ln \frac{H_{t}}{L_{t}}\right)
$$

It can be reasonably assumed that the stock of human capital related to education is proportional to the number of skilled workers $\left(H_{t}=\alpha L_{t}^{s}\right)$ and that the supply of raw labor sums up skilled and unskilled workers $\left(L_{t}=L_{t}^{s}+L_{t}^{u}\right)$. We then have

$$
\begin{aligned}
\ln \frac{H_{t}}{L_{t}} & =\ln (\alpha)+\ln \left(\frac{L_{t}^{s}}{L_{t}^{s}+L_{t}^{u}}\right) \\
& =\ln (\alpha)+\ln \left(\frac{L_{n, t}^{s}}{L_{n, t}^{s}+L_{n, t}^{u}}\right)+\ln \left(1+\frac{L_{m, t}^{s}}{L_{n, t}^{s}}\right)-\ln \left(1+\frac{L_{m, t}^{s}}{L_{n, t}^{s}+L_{n, t}^{u}}+\frac{L_{m, t}^{u}}{L_{n, t}^{s}+L_{n, t}^{u}}\right)
\end{aligned}
$$

so that the contribution of immigration $\left(I M C_{t}\right)$ to the return to schooling becomes:

$$
I M C_{t}=(1-\rho)\left[\ln \left(1+\frac{L_{m, t}^{s}}{L_{n, t}^{s}}\right)-\ln \left(1+\frac{L_{m, t}^{s}}{L_{n, t}^{s}+L_{n, t}^{u}}+\frac{L_{m, t}^{u}}{L_{n, t}^{s}+L_{n, t}^{u}}\right)\right]
$$

This contribution is much lower than in the BFK specification. Using the same population data as before, immigration explains only 6 percent of the high school premium changes between 1940 and 2000 . The impact on the wage ratio is lower since $\ln \frac{W_{t}^{s}}{W_{t}^{u}} \approx \ln \left(1+\frac{W_{t}^{H}}{W_{t}^{L}}\right)$. General equilibrium effects are likely to reduce the impact of immigration on wage differential since natives' education choices are endogenous. However, the choice of the relevant production function has a major impact on the contribution of immigration to wage inequality. As shown in table 4, our approach predicts a .5 percent contribution of immigration to the wage differential between medium and low-skilled. With a lower elasticity of 
substitution, such a contribution could rise to 1.5 percent. Consequently, more than 98 percent of wage differential is explained by natives supplies and demand changes.

Impact on inequality. The minor impact on wage differentials translated into a minor impact on income inequality (Table 3). By 2000, the US postwar immigration has increased the Gini index by 1.23 percent. Note that the inequality impact of immigration was negative until the 1970's. The cutoff of immigration would have increased the Gini index by .31 percent in the 1950's: the average education level of immigrants was slightly higher than the level of natives before the 1965 immigration act and became much lower in the recent decades. Before 1965, a cutoff of immigration would have increased the P90/P10 ratio, mainly through the P90/P50 ratio. After 1965, the "no immigration" variant reduces the P50/P10 ratio. Hence, the current impact of immigration on inequality is mainly due to the large number of low-skill workers compared to the medium skilled.

Impact on taxes. Although the labor market impact is rather small, the impact of immigration on public finance is larger. Immigrants are less educated than natives and are particularly prone to use welfare programs. But they are characterized by a younger age structure and higher fertility rates. Hence, immigration has a beneficial effect on the ratio of tax payers to the beneficiaries of the welfare state. The "no immigration" variant predicts a sharp increase in the old age dependency ratio and a rise in public transfers. Without postwar immigration, the share of public transfers in GDP would be .3 point higher and the adjusted tax rate on consumption would be 1.1 percent higher. The fiscal gain from immigration becomes important after the 1970's and is expected to increase until 2040-2050 given the impact of immigration on the average fertility rate and the growth rate of the US population.

These results are in the line of other studies on the fiscal impact of immigration. Using a partial equilibrium model, Lee and Miller (2000) find that the overall present discounted value of the effect of immigration is positive, with significant variations over time. The estimated long-run fiscal impact of 100,000 more immigrants (with average characteristics) per year would be a decrease in taxes by near 1\%. Razin and Sadka (1999, 2004) show evidence that even though the immigrants may be low-skilled and net beneficiaries of a pension system, nevertheless they may lead to a lower tax burden and less redistribution than would be the case with no immigration.

Impact on welfare. Are there winners and losers from the US postwar immigration? We answer this question by computing the consumption-equivalent level of utility of different native cohorts by educational attainment. Figure 2 represents the welfare impact of the "no immigration" variant as percentage of deviation from the baseline for the different cohorts and skill groups considered. All cohorts and education groups have gained from the postwar immigration. Cohorts born between 1950 and 1980 are the major beneficiaries, with a gain peaking at about 1 percent. The gains are smaller but significant 
(about .5 percent) for subsequent cohorts. Once again, this result is in sharp contrast with Borjas (1999b) who placed the immigration debate on redistributive ground rather than on efficiency: because post-1965 immigration is disproportionately unskilled, he concluded to a negative impact on unskilled natives whereas medium and high-skill workers should win. According to our results, the redistributive impact of immigration is quite low (high-skill workers experiences slightly higher gains than low-skill workers) and the net gain is strong. Such a positive welfare effect of immigration have already been advanced by Fehr and al. (2004). Assuming a doubling of immigration in the US, they show that almost all cohorts and skill groups realize welfare gains, ranging from 0.01 to 1.6 percent.

Figure 2: Welfare by cohort - "No immigration" in \% of the baseline

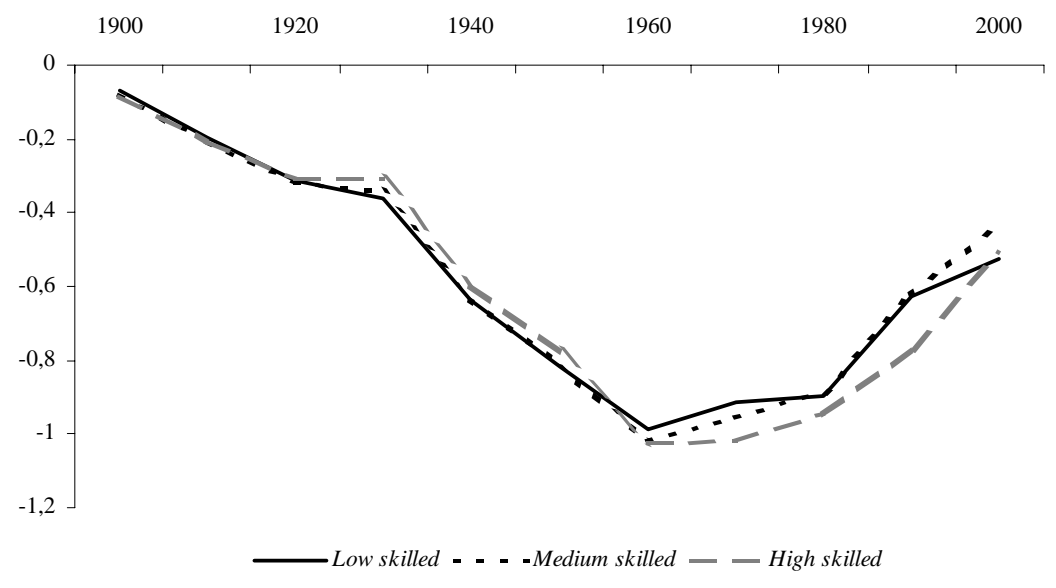

Natives' utility level is affected through three main channels: wages, taxation and interest rates. In table 5, we disentangle welfare changes by simulating alternative partial equilibrium models in which wages, tax and interest rate responses are successively neutralized. Such a method allows us to compute the contribution of each component to welfare. Given feedback effects, the sum of all contributions does not exactly replicate the result of the full general equilibrium simulation. However, the residual term is quite low. In each skill group, the wage response is more than compensated by the fiscal and the interest rate response to immigration.

Contrary to expectation, the wage effect is always positive for the different skill groups (except for the 1900 cohorts) and eases the negative effects of the two other factors. Indeed, this wage effect could be disentangle between a "raw labor" effect (arising from the reduction of the labor/capital ratio) and a "human capital return" effect (arising from competition on the labor market between immigrants and natives of the same skill). The "raw labor" effect has a positive impact on the welfare of the different 
skill groups whereas the "human capital return" effect is particularly detrimental for high-skill natives.

Whatever the skill group and cohort considered, the first effect always dominates the second one.

Table 5. Disentangling the welfare effect of immigration $(a, b)$

\begin{tabular}{|c|c|c|c|c|c|c|c|c|c|}
\hline & & 1900 & 1920 & 1940 & 1960 & 1980 & 2000 & 2020 & Long run \\
\hline Low-skill workers & Total effect & $-0,069$ & $-0,312$ & $-0,638$ & $-0,985$ & $-0,899$ & $-0,525$ & $-0,582$ & $-0,360$ \\
\hline \multirow[t]{5}{*}{ (No immigration) } & Fiscal effect & $-0,063$ & $-0,218$ & $-0,430$ & $-0,717$ & $-0,909$ & $-1,048$ & $-1,088$ & $-0,910$ \\
\hline & Interest rate effect & $-0,004$ & $-0,095$ & $-0,261$ & $-0,625$ & $-0,750$ & $-0,700$ & $-0,726$ & $-0,496$ \\
\hline & Wage effect & $-0,002$ & 0,000 & 0,053 & 0,356 & 0,762 & 1,240 & 1,250 & 1,061 \\
\hline & Including raw labor & $-0,001$ & 0,012 & 0,089 & 0,421 & 0,829 & 1,263 & 1,248 & 1,102 \\
\hline & Including human capital return & 0,000 & $-0,011$ & $-0,036$ & $-0,065$ & $-0,066$ & $-0,022$ & 0,001 & $-0,040$ \\
\hline \multirow{6}{*}{$\begin{array}{l}\text { Medium-skill workers } \\
\text { (No immigration) }\end{array}$} & Total effect & $-0,080$ & $-0,316$ & $-0,630$ & $-1,019$ & $-0,889$ & $-0,428$ & $-0,676$ & $-0,491$ \\
\hline & Fiscal effect & $-0,070$ & $-0,226$ & $-0,435$ & $-0,722$ & $-0,912$ & $-1,047$ & $-1,087$ & $-0,910$ \\
\hline & Interest rate effect & $-0,007$ & $-0,105$ & $-0,269$ & $-0,648$ & $-0,770$ & $-0,623$ & $-0,695$ & $-0,488$ \\
\hline & Wage effect & $-0,003$ & 0,015 & 0,074 & 0,350 & 0,797 & 1,260 & 1,122 & 0,918 \\
\hline & Including raw labor & $-0,001$ & 0,013 & 0,109 & 0,556 & 1,228 & 1,790 & 1,726 & 1,459 \\
\hline & Including human capital return & $-0,002$ & 0,002 & $-0,035$ & $-0,204$ & $-0,424$ & $-0,518$ & $-0,592$ & $-0,531$ \\
\hline High-skill workers & Total effect & $-0,085$ & $-0,308$ & $-0,592$ & $-1,027$ & $-0,945$ & $-0,513$ & $-0,932$ & $-0,735$ \\
\hline \multirow[t]{5}{*}{ (No immigration) } & Fiscal effect & $-0,073$ & $-0,229$ & $-0,437$ & $-0,723$ & $-0,913$ & $-1,047$ & $-1,086$ & $-0,910$ \\
\hline & Interest rate effect & $-0,008$ & $-0,111$ & $-0,255$ & $-0,615$ & $-0,736$ & $-0,493$ & $-0,626$ & $-0,437$ \\
\hline & Wage effect & $-0,005$ & 0,031 & 0,099 & 0,310 & 0,707 & 1,041 & 0,790 & 0,617 \\
\hline & Including raw labor & $-0,002$ & 0,014 & 0,130 & 0,650 & 1,459 & 2,053 & 1,951 & 1,608 \\
\hline & Including human capital return & $-0,003$ & 0,016 & $-0,031$ & $-0,337$ & $-0,738$ & $-0,990$ & $-1,137$ & $-0,972$ \\
\hline \multirow{6}{*}{$\begin{array}{l}\text { Low-skill workers } \\
\text { (Selected) }\end{array}$} & Total effect & 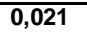 & 0,032 & 0,214 & 0,574 & 0,952 & 1,260 & 1,315 & 1,146 \\
\hline & Fiscal effect & 0,014 & 0,036 & 0,148 & 0,344 & 0,575 & 0,783 & 0,811 & 0,639 \\
\hline & Interest rate effect & 0,007 & $-0,027$ & $-0,009$ & 0,076 & 0,161 & 0,156 & 0,078 & $-0,037$ \\
\hline & Wage effect & 0,000 & 0,024 & 0,075 & 0,153 & 0,214 & 0,317 & 0,423 & 0,540 \\
\hline & Including raw labor & 0,000 & 0,022 & 0,074 & 0,146 & 0,190 & 0,279 & 0,376 & 0,499 \\
\hline & Including human capital return & 0,000 & 0,002 & 0,001 & 0,008 & 0,024 & 0,038 & 0,046 & 0,041 \\
\hline \multirow{6}{*}{$\begin{array}{l}\text { Medium-skill workers } \\
\text { (Selected) }\end{array}$} & Total effect & 0,023 & 0,008 & 0,183 & 0,522 & 0,774 & 0,965 & 0,952 & 0,897 \\
\hline & Fiscal effect & 0,015 & 0,037 & 0,153 & 0,349 & 0,578 & 0,784 & 0,810 & 0,639 \\
\hline & Interest rate effect & 0,007 & $-0,029$ & $-0,005$ & 0,094 & 0,171 & 0,146 & 0,058 & $-0,036$ \\
\hline & Wage effect & 0,001 & 0,000 & 0,034 & 0,078 & 0,024 & 0,034 & 0,083 & 0,293 \\
\hline & Including raw labor & 0,000 & 0,024 & 0,089 & 0,178 & 0,263 & 0,391 & 0,520 & 0,660 \\
\hline & Including human capital return & 0,001 & $-0,023$ & $-0,055$ & $-0,099$ & $-0,239$ & $-0,356$ & $-0,434$ & $-0,364$ \\
\hline \multirow{6}{*}{$\begin{array}{l}\text { High-skill workers } \\
\text { (Selected) }\end{array}$} & Total effect & 0,024 & $-0,020$ & 0,138 & 0,447 & 0,567 & 0,606 & 0,530 & 0,585 \\
\hline & Fiscal effect & 0,016 & 0,038 & 0,155 & 0,351 & 0,579 & 0,784 & 0,810 & 0,639 \\
\hline & Interest rate effect & 0,007 & $-0,031$ & 0,004 & 0,110 & 0,173 & 0,124 & 0,026 & $-0,032$ \\
\hline & Wage effect & 0,001 & $-0,027$ & $-0,020$ & $-0,014$ & $-0,185$ & $-0,300$ & $-0,303$ & $-0,021$ \\
\hline & Including raw labor & 0,000 & 0,025 & 0,104 & 0,196 & 0,300 & 0,446 & 0,588 & 0,727 \\
\hline & Including human capital return & 0,001 & $-0,052$ & $-0,124$ & $-0,209$ & $-0,484$ & $-0,742$ & $-0,886$ & $-0,743$ \\
\hline
\end{tabular}

(a) Change in percent of the baseline

(b) Welfare is measured as the consumption-equivalent level of utility

Source: Authors' calculations.

The "selected" variant. Our analysis suggests that the US postwar immigration is beneficial for all the parties concerned. Would the gains from immigration be larger if the US had pursued a selective immigration policy? The "selected" variant relies on the same stocks of immigration than the baseline. It assumes that the skill distribution of immigrants converges towards the distribution of natives. In such a scenario, the average education level of immigrants increases but the average experience decreases (immigrants have less experience but more schooling). Such a scenario induces the same effects on the skill premium, wage inequality and taxes than the "no immigration" variant (Table 3). The magnitude of the effects is usually lower.

As appearing on figure 3 and table 5, all natives would have gained from a stronger selection: all determinants of the utility level are positively affected. Contrary to the "no immigration" variant, the distributive impact are more important. A stronger selection would obviously be more profitable to low- 
skill workers than to medium and high-skill workers. For recent cohorts, gains for the low-skilled are twice as large as for the highly skilled.

Figure 3: Welfare by cohort - "Selected" in \% of the baseline

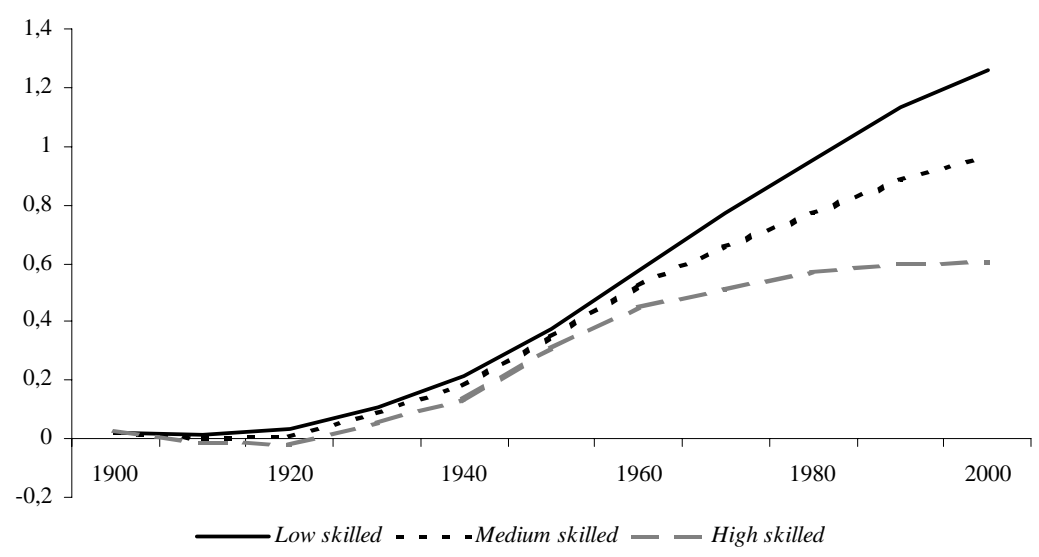

\section{Discussion}

In this paper, we develop a computable general equilibrium model to simulate the effect of the US postwar immigration on the economy. Using a backsolving calibration method, our baseline scenario matches the evolution of the US economy between 1940 and 2000. Then we use two counterfactual variants: the "no immigration" variant considers a cutoff of migration flows after 1940; the "selected" variant assumes an identical distribution of skills for natives and immigrants. Our analysis reveal three striking results.

- first, although our unit of analysis is national (and not local), the labor market impact of immigration is very small. Distinguishing the major attributes of workers (raw labor, experience, education) instead of classifying workers by group reduces the relative changes induced by immigration on the labor market. A 10 percent increase in immigration only decreases the average wage by 1 percent, a figure which is compatible with spatial correlation studies;

- second, immigration is beneficial for all. Every skill groups in every cohorts are gaining from the postwar immigration. Contrary to common views, immigration induces strong efficiency gains but small redistributive effects. These gains are closely related to fiscal externalities (the permanent entry of young immigrants decreases the equilibrium tax rate, although immigrants cost more than 
natives in all age classes) and to a small immigration surplus (immigration increases the return on capital);

- Third, all generations would have benefited from a stronger selection of immigrants. Selection would have particularly benefited to low-skill workers.

The choice of a production function has a deep impact on the results. Our results suggest that (i) the efficiency impact of immigration should not be underestimated and that (ii) the redistributive effects are likely to be small compared to skill biased changes on the demand-side. Of course, these conclusions could be nuanced by considering various externalities associated to human capital accumulation. For example, we assume that the effect of immigration on the average level of education has no effect on technical changes (especially skill biased technical changes). Assuming a relationship between the average level of education and skill biases would alter the results. By reducing the average education per worker, the US postwar immigration would have lower the magnitude of skill biased technical changes. Such a technical dimension has been disregarded in the immigration debate and would obviously deserves more attention.

\section{References}

[1] Auerbach, Alan J. and Lawrence J. Kotlikoff, 1987, Dynamic Fiscal Policy, Cambridge.

[2] Auerbach, Alan J. and Philip Oreopoulos, 2000, "The fiscal effects of US immigration: a generational accounting perspective", in: Poterba, James (ed), Tax policy and the economy 14, 123-156.

[3] Ben-Porath, Yoram (1967), "The production of human capital and the life cycle of earnings", Journal of Political Economy 75(4), 352-365.

[4] Blondal, Sveinbjorn and Stefano Scarpetta, 1997, "Early retirement in OECD countries: the role of social security systems", OECD-Economic Studies 29, 7-54.

[5] Bonin, Holger, Bernd Raffelhüschen and James Walliser, 2000, "Can immigration alleviate the demographic burden", FinanzArchiv 57.

[6] Borjas, George J., 1994, "The economics of immigration", Journal of Economic Literature 32, 16671717.

[7] Borjas, George J.,1999a, "Immigration and welfare magnets", Journal of Labor Economics, 17, 607637.

[8] Borjas, George J., 1999b, Heaven's door: immigration policy and the American economy, Princeton University Press. 
[9] Borjas, George J., 2003, "The labor demand curve is downward sloping: reexamining the impact of immigration on the labor market", Quarterly Journal of Economics, 1335-1374.

[10] Borjas, George J., Richard B. Freeman, Lawrence F. Katz, 1997, "How Much Do Immigration and Trade Affect Labor Market Outcomes?”, Brookings Papers on Economic Activity Vol 1997, №10, $1-90$.

[11] Brown, Carey, 1990, "Episodes in the public debt history of the United States", in: Rudiger Dornbush and Mario Draghi, Public debt management: theory and history, 229-254, Cambridge.

[12] Card, David and Thomas Lemieux (2001), "Can falling supply explain the rising return to college for younger men? A cohort-based analysis", Quarterly Journal of Economics 116(2), 705-746.

[13] De la Croix, David and Frédéric Docquier, 2003, "Diverging patterns of education premium and school attendance in France and the US: a Walrassian view", IZA Discussion paper n. 846, IZABonn.

[14] Fehr, Hans, Sabine Jokisch and Lawrence J. Kotlikoff, 2004, "The role of immigration in dealing with the developed world's demographic transition", NBER Working Paper 10512.

[15] Friedberg, Rachel M. and Jennifer Hunt, 1995, "The impact of immigrants on the host country wages, employment and growth", Journal of Economic Perspectives 9, 23-44.

[16] Gokhale, J., B.R. Page and J.R. Sturrock, 1999, "Generational accounts for the United States: an update", in: Auerbach, A.J., L. J. Kotlikoff and W. Leibfritz (ed.), Generational Accounting Around the World, NBER Books, The University of Chicago Press.

[17] Hao, Lingxin, 2004, "Wealth of Immigrant and Native-born Americans", International Migration Review, 38 (2), 518-546.

[18] Lee, Ronald D. and Thimothy W. Miller, 1997, "The lifetime fiscal impacts of immigrants and their descendants: a longitudinal analysis" Manuscript, Berkeley.

[19] Lee, Ronald D. and Thimothy W. Miller, 2000," Immigration, Social Security and Broader Fiscal Impacts ", American Economic Review, 90, 350-354.

[20] Razin, Assaf and Efraim Sadka, 1999, "Migration and Pension with International Capital Mobility", Journal of Public Economics 74 (1), 141-50.

[21] Razin, Assaf and Efraim Sadka, 2004, "Welfare migration: Is the net fiscal burden a good measure of its economic impact on the welfare of the native-born population?", NBER Working Paper 10682. 
[22] Rios-Rull, José-Victor, 1992, Population changes and capital accumulation: the aging of the baby boom", Manuscript. Pittsburgh: Carnegie Mellon University.

[23] Sims, Christopher, 1990, "Solving the stochastic growth model by backsolving with a particular non linear form for the decision rule", Journal of Business and Economic Statistics 8(1), 45-47.

[24] Storesletten, Kjetil, 2000, "Sustaining fiscal policy through immigration", Journal of Political Economy, 108(2), 300-323.

[25] Wasmer, Etienne, 2001a, "Between-group competition on the labour market and the rising return to skill: US and France 1964-2000", CEPR Working paper, n. 278.

[26] Wasmer, Etienne, 2001b, "Measuring human capital in the labour market: the supply of experience in 8 OECD countries", European Economic Review 45, 861-874.

\section{Appendix: Robustness to the elasticity of substitution}

The parameter $\rho$ determines the magnitude of wage responses (the intensity of the relationship between changes in factor proportions and changes in wages). Tables A1 and A2 give the economic consequences of immigration in alternative models. The model behind table A1 is calibrated with a low elasticity of substitution $(\rho=.5 ; 1 /(1-\rho)=2)$. The model behind table A2 is calibrated with a high elasticity of substitution $(\rho=.9 ; 1 /(1-\rho)=10)$. The conclusions are similar to the baseline simulation in table 3 and to the magnitude of the table 4 . 
Table A1. Economic consequences of the US immigration (lower elasticity of substitution, $\rho=.5$ )

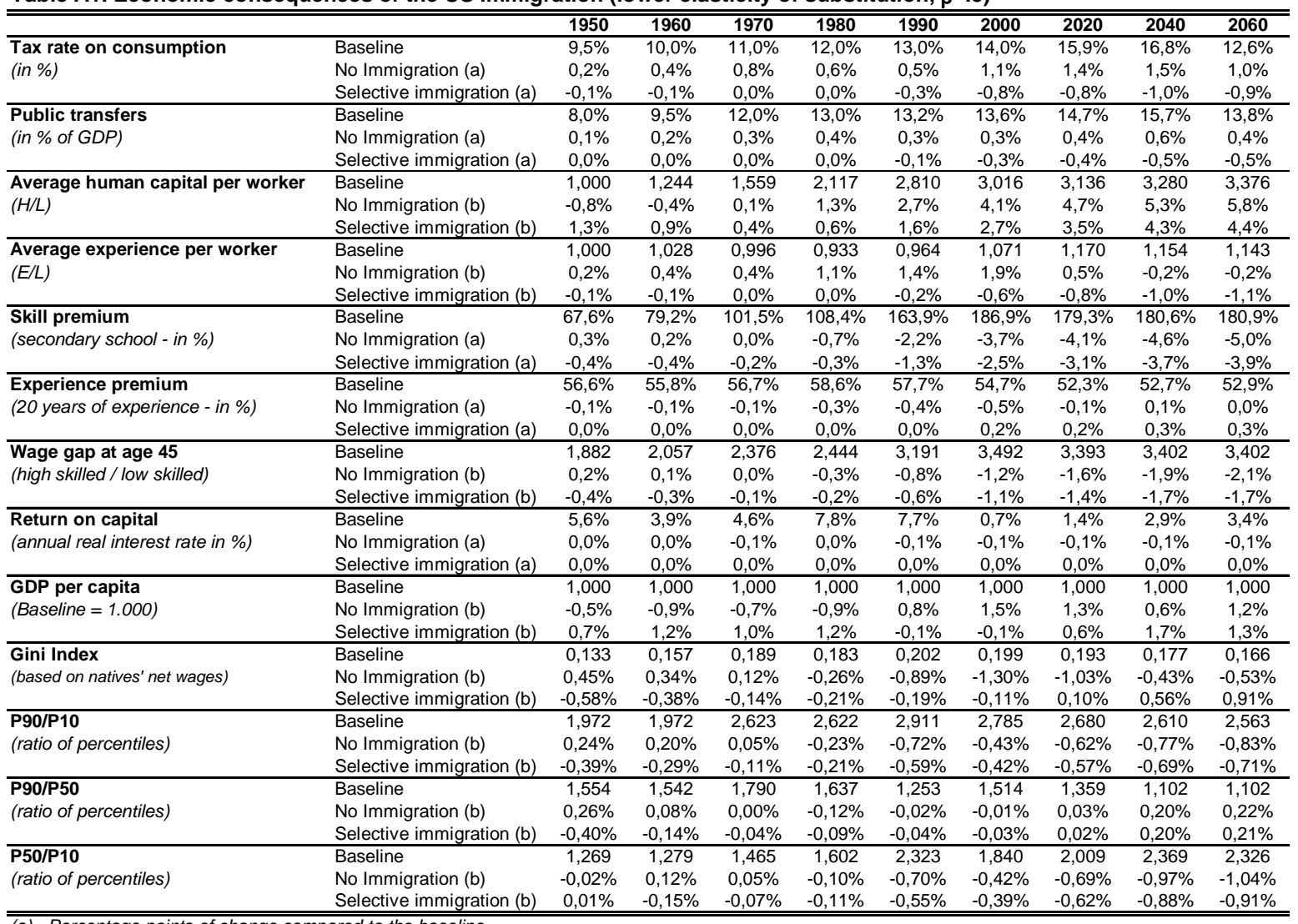

compared to the baseline

(b) Change in percent of the baseline

Source: Authors' calculations. 
Table A2. Economic consequences of the US immigration (higher elasticity of substitution, $\rho=.9$ )

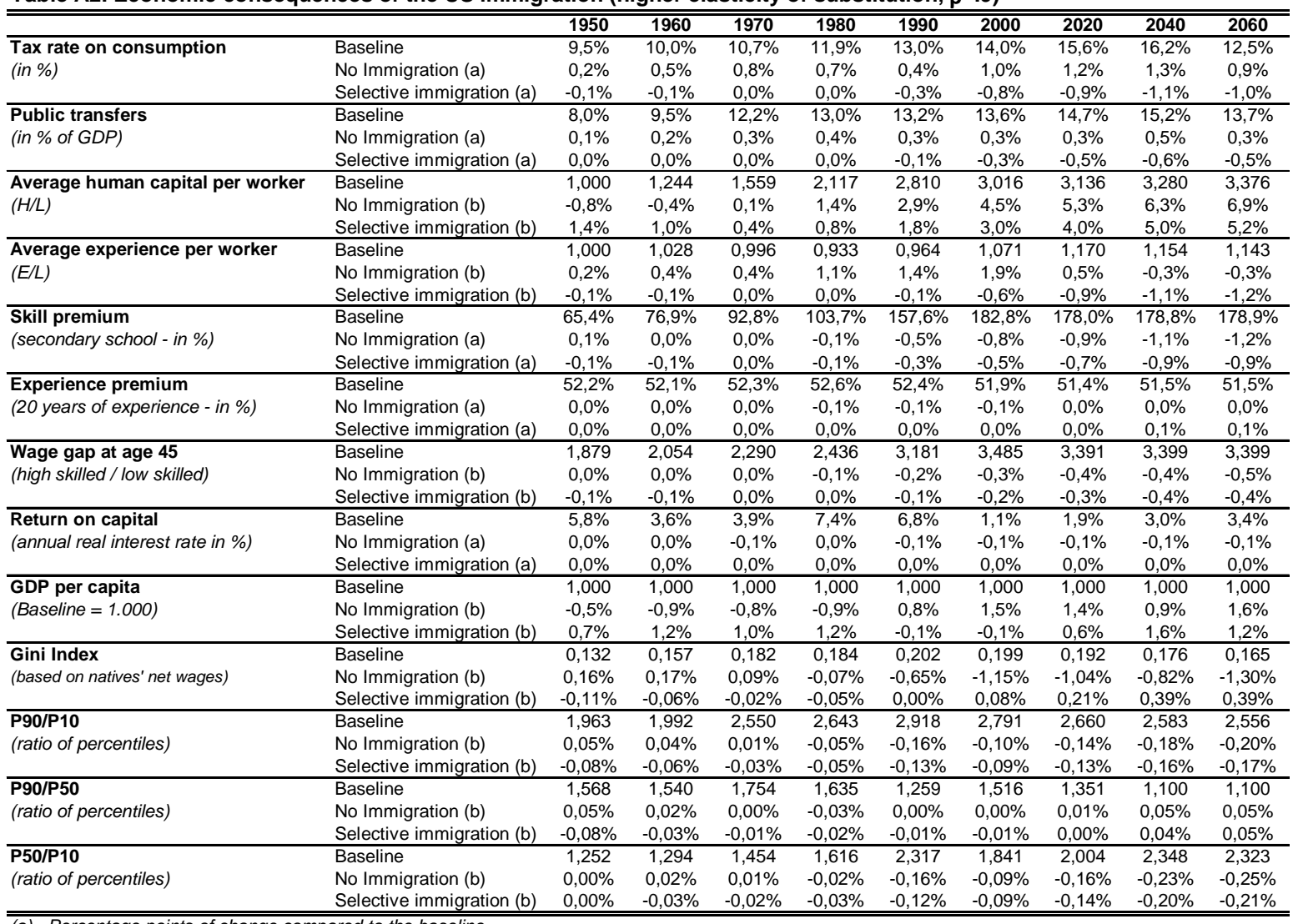

sed to the baseline

(b) Change in percent of the baseline

Source: Authors' calculations. 